\title{
Broadband Cortical Desynchronization Underlies the Human Psychedelic State
}

\author{
Suresh D. Muthukumaraswamy, ${ }^{1 *}$ Robin L. Carhart-Harris, ${ }^{2 \star}$ Rosalyn J. Moran, ${ }^{7}$ Matthew J. Brookes, ${ }^{4}$ \\ Tim M. Williams, ${ }^{5}$ David Errtizoe, ${ }^{2}$ Ben Sessa, ${ }^{5}$ Andreas Papadopoulos, ${ }^{5}$ Mark Bolstridge, ${ }^{2}$ Krish D. Singh, ${ }^{1}$ \\ Amanda Feilding, ${ }^{6}$ Karl J. Friston, ${ }^{3}$ and David J. Nutt ${ }^{2}$ \\ ${ }^{1}$ Cardiff University Brain Research Imaging Centre, School of Psychology, Cardiff University, Cardiff CF119BJ, United Kingdom, ${ }^{2}$ Imperial College London, \\ Centre for Neuropsychopharmacology, Division of Brain Sciences, Faculty of Medicine, London W12 ONN, United Kingdom, ${ }^{3}$ Wellcome Trust Centre for \\ Neuroimaging, University College London, London WC1N 3BG, United Kingdom, ${ }^{4}$ Sir Peter Mansfield Magnetic Resonance Centre, Nottingham University, \\ Nottingham NG7 2RD, United Kingdom, ${ }^{5}$ Academic Unit of Psychiatry, University of Bristol, Bristol BS8 2BN, United Kingdom, ${ }^{6}$ The Beckley Foundation, \\ Beckley Park, Oxford OX3 9SY, United Kingdom, and ${ }^{7}$ Virginia Tech Carilion Research Institute, and Bradley Department of Electrical \& Computer \\ Engineering, Virginia Polytechnic Institute and State University, Roanoke, Virginia 24016
}

Psychedelic drugs produce profound changes in consciousness, but the underlying neurobiological mechanisms for this remain unclear. Spontaneous and induced oscillatory activity was recorded in healthy human participants with magnetoencephalography after intravenous infusion of psilocybin-prodrug of the nonselective serotonin $2 \mathrm{~A}$ receptor agonist and classic psychedelic psilocin. Psilocybin reduced spontaneous cortical oscillatory power from 1 to $50 \mathrm{~Hz}$ in posterior association cortices, and from 8 to $100 \mathrm{~Hz}$ in frontal association cortices. Large decreases in oscillatory power were seen in areas of the default-mode network. Independent component analysis was used to identify a number of resting-state networks, and activity in these was similarly decreased after psilocybin. Psilocybin had no effect on low-level visually induced and motor-induced gamma-band oscillations, suggesting that some basic elements of oscillatory brain activity are relatively preserved during the psychedelic experience. Dynamic causal modeling revealed that posterior cingulate cortex desynchronization can be explained by increased excitability of deep-layer pyramidal neurons, which are known to be rich in $5-\mathrm{HT}_{2 \mathrm{~A}}$ receptors. These findings suggest that the subjective effects of psychedelics result from a desynchronization of ongoing oscillatory rhythms in the cortex, likely triggered by $5-\mathrm{HT}_{2 \mathrm{~A}}$ receptor-mediated excitation of deep pyramidal cells.

\section{Introduction}

Psychedelics have been used in various human cultures for thousands of years. Recent studies have shown that a single dose of a psychedelic can produce remarkable effects, such as profound spiritual experiences and long-term changes in personality (MacLean et al., 2011). Other research suggests that psychedelics may be useful in treating alcohol dependence (Krebs and Johansen, 2012), obsessive-compulsive disorder (Moreno et al., 2006), and anxiety related to terminal illness (Grob et al., 2011). It has also been proposed that psychedelics may model certain psychotic symptoms (Vollenweider et al., 1998; Carhart-Harris et al., 2012b). The neural mechanisms mediating all of these effects

\footnotetext{
Received May 13, 2013; revised Aug. 5, 2013; accepted Aug. 8, 2013

Author contributions: S.D.M., R.L.C.-H., A.F., and D.J.N. designed research; S.D.M., R.L.C.-H., T.M.W., D.E., B.S., A.P., and M.B. performed research; S.D.M., R.J.M., M.J.B., K.D.S., and K.J.F. contributed unpublished reagents/ analytic tools; S.D.M. and R.L.C.-H. analyzed data; S.D.M., R.L.C.-H., R.J.M., M.J.B., K.J.F., and D.J.N. wrote the paper.

This research received financial and intellectual support from the Beckley Foundation and was conducted as part of the Beckley-Imperial Psychedelic Research Programme. The authors thank Alison Diaper and the research volunteers.

*S.D.M. and R.L.C.-H. contributed equally to this work.

The authors declare no competing financial interests.

Correspondence should be addressed to Robin L. Carhart-Harris, Imperial College London, Centre for Neuropsychopharmacology, Division of Brain Sciences, Faculty of Medicine, London W12 ONN, United Kingdom. E-mail: r.carhart-harris@imperial.ac.uk.

DOI:10.1523/JNEUROSCI.2063-13.2013

Copyright $\odot 2013$ the authors $\quad 0270-6474 / 13 / 3315171-13 \$ 15.00 / 0$
}

remain largely unknown, but it is known that all psychedelics are $5-\mathrm{HT}_{2 \mathrm{~A}}$ receptor agonists (Glennon et al., 1984; Vollenweider et al., 1998).

Electroencephalographic (EEG) studies in humans have found decreased cortical synchrony after ingestion of the psychedelic plant brew ayahuasca (Riba et al., 2004). Local field potential recordings in rats have demonstrated that both serotonin (Puig et al., 2010) and the 5- $\mathrm{HT}_{2 \mathrm{~A}}$ receptor agonist 1-(2,5dimethoxy-4-iodophenyl-2-aminopropane) (DOI; Wood et al., 2012) reduce high-frequency brain activity. However, the analysis of high-frequency time-series components is difficult with EEG recordings (Whitham et al., 2007, 2008). Magnetoencephalography (MEG), the magnetic counterpart of EEG, is more robust to the tissue conduction effects present in EEG and provides both more accurate source localization and better characterization of high-frequency $(>20 \mathrm{~Hz})$ activity due to the decreased influence of muscle artifacts (Whitham et al., 2007). For these reasons, here, for the first time, we used MEG to directly record broadband $(1-100 \mathrm{~Hz})$ neural activity during the human psychedelic state.

Recent functional magnetic resonance imaging (fMRI) studies in healthy participants found decreased blood flow and venous oxygenation in the thalamus, putamen, and association cortices after psilocybin administration, implying decreased neural activity in these regions (Carhart-Harris et al., 2012a). How- 
ever, fMRI measures changes in neural activity indirectly via changes in brain blood flow, which can be problematic when studying a drug that might directly affect the cerebral vasculature. Moreover, the poor temporal resolution of the blood oxygen level-dependent (BOLD) signal of fMRI provides limited information about the higher-frequency neural dynamics underlying different states of consciousness. Thus, to directly assess the effects of a psychedelic on neural activity in the human brain, we performed MEG recordings.

Fifteen healthy volunteers with prior experience with psychedelics received a bolus infusion of $10 \mathrm{ml}$ of saline in one MEG session and $2 \mathrm{mg}$ of psilocybin in $10 \mathrm{ml}$ of saline in a second session, in a within-subjects single-blind design. Each restingstate recording lasted $11 \mathrm{~min}$. There was a $5 \mathrm{~min}$ preinfusion baseline period, followed by a $60 \mathrm{~s}$ infusion of psilocybin, and a 5 min postinfusion period. The subjective effects of psilocybin begin within seconds when administered in this way, allowing the capture of the transition from normal waking consciousness to the psychedelic state. Participants were instructed to relax and keep their eyes open for the duration of the scan, and a fixation point was presented throughout. Approximately $6 \mathrm{~min}$ after the infusion, participants performed a visuomotor task designed to elicit stimulus-induced gamma-band oscillations in the primary visual and motor cortices. After exiting the scanner, participants completed a 23-item questionnaire scoring specific aspects of their psychedelic experience.

\section{Materials and Methods}

\section{Participants}

Fifteen healthy male participants (mean age, 34.5 years, SD, 2.3 years) gave informed consent to participate in the study. The study was approved by a National Health Service research ethics committee. A physical examination, including electrocardiogram (ECG), routine blood tests, and urine test for drugs of abuse was carried out. A psychiatric assessment was conducted, and participants disclosed their drug-taking histories. Exclusion criteria were as follows: $<21$ years of age, pregnancy, personal or immediate family history of psychiatric disorder, substance dependence, cardiovascular disease, claustrophobia, blood or needle phobia, or a significant adverse response to a hallucinogenic drug. All participants had previous experience with a hallucinogenic drug but not within 6 weeks of the study.

\section{Drug infusion and protocol}

Because psilocybin is known to cause long-term psychological changes (Griffiths et al., 2006, 2008, 2011; MacLean et al., 2011; of unknown biological substrate), which far outlive the drug half-life, we opted for a fixed-order design. Participants underwent two scans on each day, one using a placebo saline infusion, and one using psilocybin. The psilocybin was always received second, but participants were blinded to the order of infusion. To minimize any potential order effect (see Discussion), we compared the postinfusion data with a preinfusion baseline. For stimulus-induced activity, we have already demonstrated that the protocols used are extremely robust to time-of-day and repeated-exposure effects (Muthukumaraswamy et al., 2010, 2013a,b). Participants were seated in the MEG with their heads partly stabilized by a plastic chin rest. In each scan session, 5 min of resting MEG was recorded, and then the participant was infused over $60 \mathrm{~s}$ ( $2 \mathrm{mg}$ in $10 \mathrm{ml}$ of saline). The subjective effects of psilocybin begin within seconds (Carhart-Harris et al., 2011, 2012a) of infusion, and hence we recorded 5 min of resting MEG data immediately after infusion. At this point, participants were asked to provide a rating of their subjective "high" on a scale between 0 and 100 using button press in the scanner. Following this, the $10 \mathrm{~min}$ visuomotor stimulation task was performed (described below). Participants provided another rating after completion of this task. Participants' pulse rate and blood oxygenation level were continually monitored throughout the experiment. After scanning, participants were asked to complete a 23 -item subjective rating scale pertaining to characteristic effects of psychedelics. The rating scale structure was informed by the five-dimension altered states of consciousness rating scale of Dittrich (1998), but the items were selected based on our own previous empirical work (Carhart-Harris et al., 2011, 2012a), and were reduced to 22 items (plus 1 control item) for concision and to reflect subjective phenomena that are most characteristic of the psychedelic state.

\section{Visuomotor paradigm}

Following the resting recordings, participants were presented with a visual stimulus consisting of a vertical, stationary, maximum-contrast, 3 cycles $/{ }^{\circ}$, square-wave grating presented on a mean luminance background. The stimulus subtended $8^{\circ}$ both horizontally and vertically with a small red fixation square located at the center of the stimulus, which remained on for the entire stimulation protocol (Muthukumaraswamy et al., 2009; Swettenham et al., 2009). The stimulus was presented on a Mitsubishi Diamond Pro 2070 monitor controlled by the Psychophysics Toolbox (Brainard, 1997; Pelli, 1997). The screen size was $1024 \times 768$ pixels, and the monitor frame rate was $100 \mathrm{~Hz}$. The monitor was outside the magnetically shielded room and was viewed directly from within, at $2.15 \mathrm{~m}$, through a cutaway portal in the shield. The duration of each stimulus was $1.5-2 \mathrm{~s}$ followed by $2 \mathrm{~s}$ of the fixation square only. Participants were instructed to fixate for the entire experiment and to maintain attention where instructed to abduct their index finger at the termination of each stimulation period. This recording took $\sim 10 \mathrm{~min}$.

\section{$M E G$ acquisition and analysis}

Whole-head MEG recordings were made using a CTF 275-channel radial gradiometer system sampled at $600 \mathrm{~Hz}(0-150 \mathrm{~Hz}$ bandpass filter). An additional 29 reference channels were recorded for noise cancellation purposes, and the primary sensors were analyzed as synthetic third-order gradiometers (Vrba and Robinson, 2001). Three of the 275 channels were turned off due to excessive sensor noise. At the onset of each stimulus presentation, a transistor-transistor logic pulse was sent to the MEG system. Participants were fitted with three electromagnetic head coils (nasion and preauriculars), which were localized relative to the MEG system immediately before and after the recording session. Additional vertical and horizontal electroculograms, an ECG, and an electromyogram (EMG) from the right first dorsal interosseus were also recorded with the MEG. Additionally, finger movements of the right index finger during the visuomotor task were recorded with an optical displacement system (Muthukumaraswamy, 2010).

For source localization, a 3D Fast Spoiled Gradient Recalled (FSPGR) anatomical MRI scan was obtained using a 3 T General Electric HDx scanner with an eight-channel receive-only head receptive-field coil from each participant. Fast spoiled gradient echo scans were acquired in an oblique-axial orientation, with $1 \mathrm{~mm}$ isotropic voxel resolution. To achieve MRI/MEG coregistration, for source localization, the fiduciary markers were placed at fixed distances from anatomical landmarks identifiable in participants' anatomical MRIs (tragus, eye center). Fiduciary locations were verified afterward using digital photographs.

\section{$M E G$ analysis}

Preprocessing of resting data. Five minutes of data obtained immediately before the beginning of infusion and immediately after the cessation of infusion were extracted from the continuous recording, high-pass filtered at $1 \mathrm{~Hz}$, and segmented into epochs of $2 \mathrm{~s}$ in length. We discarded the MEG data during infusion as it was potentially confounded, and as participants could sometimes detect the solution entering their arm or hear the physician move as they dispensed the solution (the magnetically shielded room is nearly silent). Hence, there were 150 epochs both preinfusion and postinfusion for analysis. Each epoch was visually inspected, and those with gross artifacts (e.g., head movements, jaw clenches) were removed from the analysis. One participant was removed from all MEG analyses due to excessive artifacts (head movements and jaw clenching).

Source localization of resting oscillatory changes. To localize druginduced changes in oscillatory power, we used the beamformer algorithm synthetic aperture magnetometry (SAM; Robinson and Vrba, 1999). In addition to localizing activity, beamformers are effective in 
detecting and suppressing a number of potential artifacts, including muscle (Carl et al., 2012), ocular (Bardouille et al., 2006), dental (Cheyne et al., 2007), and stimulator artifacts (Litvak et al., 2010). Global covariance matrices were calculated for the following six bandpass-filtered versions of the datasets: delta $(1-4 \mathrm{~Hz})$, theta $(4-8 \mathrm{~Hz})$, alpha $(8-13 \mathrm{~Hz})$, beta $(13-30 \mathrm{~Hz})$, low gamma $(30-50 \mathrm{~Hz})$, and high gamma $(50-100 \mathrm{~Hz})$. These frequency bands were based on previous investigations of restingstate MEG data (Brookes et al., 2011; Hall et al., 2013). Based on these covariance matrices, using the beamformer algorithm (Robinson and Vrba, 1999), a set of beamformer weights was computed for all voxels in the brain at $4 \mathrm{~mm}$ isotropic voxel resolution. A multiple local-spheres (Huang et al., 1999) volume conductor model was derived by fitting spheres to the brain surface extracted by the FSL Brain Extraction Tool (Smith, 2002). For SAM imaging, virtual sensors were constructed at each beamformer voxel and Student's $t$ images of source power changes computed for postinfusion versus preinfusion epochs.

Group statistical analysis was conducted using software from the FSL software library (www.fmrib.ox.ac.uk/fsl/). Individual SAM images were first spatially normalized onto the MNI (T1) average brain using the FMRIB Linear Affine Registration Tool (FLIRT). This was done by first obtaining a set of warping parameters by registering the participant's anatomical MRI with the average brain and then applying these parameters to the SAM source power maps. Statistical group analysis of the normalized SAM images was performed on each condition and frequency band image using nonparametric permutation testing (Nichols and Holmes, 2002; Singh et al., 2003). Five thousand permutations were calculated for each statistical test conducted with a $5 \times 5 \times 5 \mathrm{~mm}$ Gaussian smoothing kernel applied to the variance maps. We computed a paired $t$ test for the placebo versus psilocybin after and before images to reveal the drug interaction effect. $t$ images were thresholded at $p<0.05$ (corrected, two-tailed). For all bands, we used the statistical omnibus to correct for multiple comparisons, except in the $50-100 \mathrm{~Hz}$ band where we used a less conservative (Chau et al., 2004) cluster-based threshold with an initial cluster-forming threshold of 2.3 (Nichols and Holmes, 2002).

Based on the source reconstruction images, we reconstructed sources from the posterior cingulate cortex (PCC)/precuneus using the HarvardOxford Atlas. For frequency analysis of the virtual sensors, we computed power spectral density estimates using Hanning window FFTs. Statistical analysis of these was conducted using $2 \times 2$ repeated-measures ANOVA using a resampling approach in the FSL randomize (5000 permutations).

Independent component analysis network analysis. For analysis of oscillatory networks, we used the methodology described in Brookes et al. (2011) on the preprocessed MEG data. For each participant and frequency band, beamformer weights were computed on an $8 \mathrm{~mm}$ grid based on the preprocessed dataset. Beamformer time courses were then generated at every voxel and normalized by an estimate of the projected noise amplitude at that voxel. The Hilbert transform was applied to each voxel time course, and the absolute value was computed to generate an amplitude envelope of the oscillatory signals in each frequency band. The data at each voxel was downsampled to an effective sampling rate of $1 \mathrm{~Hz}$, transformed to standard (MNI) space using FLIRT in FSL, and data from all subjects were concatenated in the time dimension across subjects. Temporal independent component analysis (ICA) was applied to the concatenated datasets (separately for all six frequency bands) using the fast ICA (research.ics.tkk.fi/ica/fastica) algorithm. Prewhitening was applied to reduce the dimensionality of the source space Hilbert envelope signals to 20 principal components before ICA (Hyvärinen and Oja, 2000; Brookes et al., 2011; Hall et al., 2013). Fifteen independent components were derived for each frequency band. To reduce the number of independent components subsequently analyzed, the following strategy was applied: each component was classified as follows: (1) an artifact due to either physiological or beamformer errors (deep brainstem sources); (2) a unimodal component; or (3) a network. Since we had already localized the changes in source power, we specifically focused on components in category 3. In total, 11 such components were identified. For these components, we computed the SD of the component time course for each subject and condition. Differences in the SD of the independent component time course between placebo and psilocybin were assessed using $2 \times 2$ repeated-measures ANOVAs in those where $p<0.01$ was reported.

Dynamic causal modeling. The purpose of the dynamic causal modeling (DCM) - in the context in which we have used it here-is to link the spectral changes we observed in the PCC/precuneus with underlying synaptic changes that occurred with the drug. We focused on reconstructed source activity from the PCC/precuneus as convergent evidence from $\mathrm{AMRI}$, arterial spin labeling (ASL), and positron emission tomography (PET), and now MEG, suggests that the posterior parietal lobe is a key area involved in the human psychedelic experience (Erritzoe et al., 2009; Carhart-Harris et al., 2012a). To do this, we used dynamic causal modeling for steady-state responses previously described in a number of articles (Moran et al., 2007, 2009, 2011).

The canonical microcircuit (neural-mass) model we used here was composed of four subpopulations consisting of spiny stellate cells, inhibitory interneurons, deep pyramidal cells, and superficial pyramidal cells. The connectivity of each neural subpopulation is summarized in Figure 1. The behavior of each subpopulation is modeled with pairs of firstorder differential equations of the following form (Moran et al., 2009):

$$
\begin{gathered}
\dot{x}_{v}=x_{I}, \\
\dot{x}_{I}=\kappa \mathrm{U}-2 \kappa x_{I}-\kappa^{2} x_{v} .
\end{gathered}
$$

The column vectors $x_{v}$ and $x_{I}$ correspond to the mean voltages and currents, where each element corresponds to the hidden state of the subpopulation. These differential equations implement a convolution of a subpopulation's presynaptic input $(U)$ to produce a postsynaptic response (Fig. 1), where the rate constants $(\kappa)$ represent an inverse of a lumped parameter that accounts for all dendritic and membrane time delays. Delays between the layers are accounted for through a Jacobian expansion (Kiebel et al., 2007) and have a prior value of $1 \mathrm{~ms}$. The presynaptic input to the subpopulations comprises an endogenous component, $E$, which is a mixture of white and pink noise perturbations (these enter only the stellate cells; Table 1 , see $\alpha_{u}$ and $\beta_{u}$ in Parameters), and a scaled input of ensemble firing from each prescribed presynaptic population (the signs of these inputs are shown in Fig. 1 and implement effective excitability or gain increases and decreases). Firing rates from presynaptic subpopulations are prescribed through a sigmoidal transform $($ slope $=2 / 3$ ) dependent on their membrane depolarization (Moran et al., 2009).

$$
U=\gamma S\left(x_{v_{\text {presynaptic }}}\right)+E
$$

The output of the model is a mixture of the depolarization of each subpopulation. Since pyramidal dendrites are oriented tangentially to the cortical surface in a more "open field" configuration (Murakami and Okada, 2006), the contribution of each subpopulation is weighted and optimized during inversion. This is augmented with a parameterized channel noise component and amplifier gain to comprise the full observer function. Here we used prior weights of $20 \%$ for deep pyramidal cells $\left(x_{V_{-} \mathrm{DP}}\right), 80 \%$ for superficial pyramidal cells $\left(x_{V_{V_{-}} \mathrm{SP}}\right)$, and $20 \%$ for the stellates $\left(x_{-} V_{-} S C\right)$.

The generative model created above was then inverted (fitted to the data) to obtain the posterior densities of the parameters. In DCM, a variational Bayesian scheme (variational Laplace) is used to approximate the posterior density over parameters by maximizing the negative free energy, a bound on the log-model evidence (Friston et al. (2007)). The parameters operate as scaling values on prior expectations. The full list of parameters and the sufficient statistics of their priors is given in Table 1, and the full mass model with equations is represented in Figure 1. Most of the intrinsic connectivity $(\gamma)$ parameters that connect the different neuronal masses would represent glutamatergic or GABAergic synapses. Psilocybin acting on serotonin receptors would modulate the excitability of neuronal masses; that is, it would modulate the gain of the populations that contain these receptor types. That is, psilocybin has a neuromodulatory influence (i.e., rather than being directly GABAergic or glutamatergic). Therefore, we specifically modeled prespectral versus postspectral changes as a set of parameters $\left(\beta_{1 \ldots 4}\right)$. These four parameters effectively modeled drug-induced modulations of the gain of each population in the neuronal 

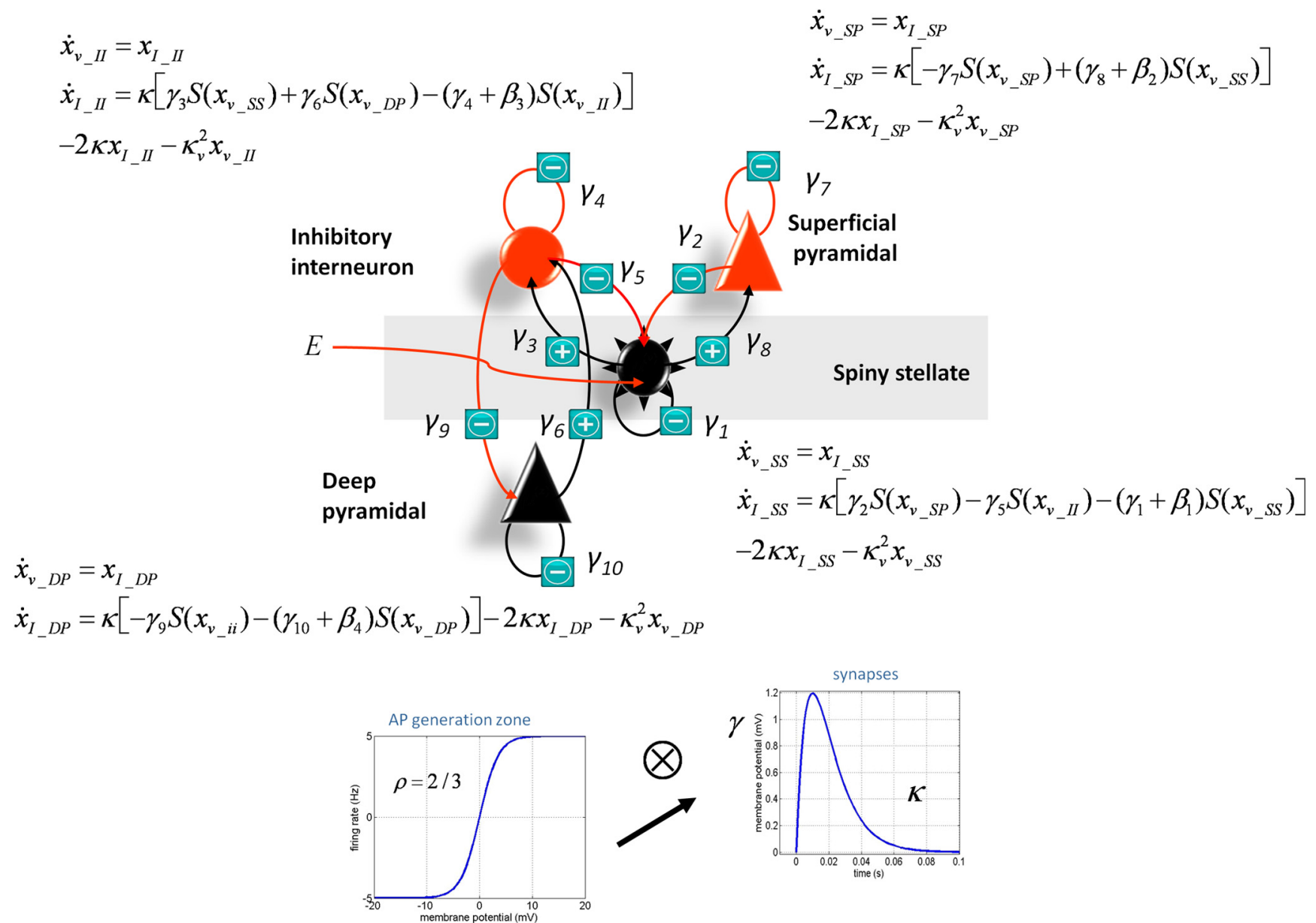

Figure 1. Summary of the neural mass model used in the dynamic causal modeling.

mass (Table 1). Parameters $\beta_{1}$-modeled changes in $\gamma_{1}$ (stellate cell gain), $\beta_{2}$-modeled changes in $\gamma_{7}$ superficial pyramidal cell gain, $\beta_{3}$-modeled inhibitory interneuron gain in $\gamma_{4}$, and $\beta_{4}$-modeled deep pyramidal cell gain in $\gamma_{10}$. Having obtained these $\beta_{1 \ldots 4}$ parameter estimates, we then performed paired $t$ tests comparing them between placebo and psilocybin infusion over subjects.

Visual and motor responses. Analysis of motor cortical responses to the offset of the visual stimulus was conducted in a very similar fashion to those we (Muthukumaraswamy, 2010, 2011; Hamandi et al., 2011; Muthukumaraswamy et al., 2013b) and others have previously reported (Jurkiewicz et al., 2006; Cheyne et al., 2008; Gaetz et al., 2010, 2011). From the continuous MEG recordings, EMG onsets were marked using an automated algorithm that marked increases in the rectified EMG signal by 3 SDs above the noise floor (Cheyne et al., 2008), subject to the constraint that they occurred within $1 \mathrm{~s}$ of the tone pip. Data were epoched from $1.5 \mathrm{~s}$ before to $3 \mathrm{~s}$ after the EMG markers. Each trial was then visually inspected and discarded for any of the following reasons: (1) excessive MEG signal artifacts (e.g., head movements/ jaw clenches); (2) irregular movement displacements (e.g., double movements); or (3) irregular EMG activity. Analysis of visual cortical responses to the onset of the grating stimulus was conducted in a very similar fashion to those we (Muthukumaraswamy et al., 2009, 2010, 2013a; Gaetz et al., 2012; Muthukumaraswamy and Singh, 2013; Perry et al., 2013; Saxena et al., 2013) and others (Adjamian et al., 2004; Brookes et al., 2005; Hall et al., 2005; Hadjipapas et al., 2007; Schwarzkopf et al., 2012) have previously reported. Data were first epoched from -1.5 to $1.5 \mathrm{~s}$ around stimulus onset, and each trial was visually inspected for data quality. Epochs with gross artifacts, such as head movements and muscle clenching, were excluded from further analysis.

For source localization of the data, we used SAM (Robinson and Vrba, 1999) with a set of beamformer weights (4 mm resolution) calculated from global covariance matrices in the gamma band $(60-90 \mathrm{~Hz}$ for motor, $35-80 \mathrm{~Hz}$ for visual). For SAM image reconstruction, virtual sensors were constructed for each beamformer voxel and Student's $t$ test images of source power changes were computed (Table 2). Using parameters from Cheyne et al. (2008), Muthukumaraswamy (2010), and Hamandi et al. (2011) for motor gamma localization, we used a baseline period of -1.3 to $1 \mathrm{~s}$, and an active period of $0-0.3 \mathrm{~s}$, while for visual cortex localization we used a baseline period of -1.5 to $0 \mathrm{~s}$, and an active period of $0-1.5 \mathrm{~s}$. After generating the source reconstruction images, the voxels with the strongest change in visual and motor cortices were located, and virtual sensors were constructed at these peak locations. To reveal the time-frequency response at a virtual sensor location, the virtual sensor was repeatedly bandpass filtered at $0.5 \mathrm{~Hz}$ frequency step intervals using an 8-Hz-wide third-order Butterworth filter from 1 to $150 \mathrm{~Hz}$ (Le Van Quyen et al., 2001; Muthukumaraswamy, 2010; Saxena et al., 2013). At each frequency step, the Hilbert transform was used to obtain the timevarying amplitude envelope, and the envelopes were then averaged across trials. In a first iteration of the analysis, we computed time-frequency spectra as the percentage change from baseline values. In a second iteration, unbaselined maps were calculated to check for differences in the prestimulus baseline spectra (Muthukumaraswamy et al., 2013b; Saxena et al., 2013). From the baseline time-frequency spectra, amplitude envelopes were calculated for beta $(15-30 \mathrm{~Hz})$ and gamma $(60-90 \mathrm{~Hz}$; Muthukumaraswamy et al., 2013b) bands for the motor cortex, and for alpha $(8-13 \mathrm{~Hz})$ and gamma $(35-80 \mathrm{~Hz})$ bands in the visual cortex. We searched for differences in the frequency band-limited envelopes with paired $t$ tests at each sample point using a resampling approach (Nichols and Holmes, 2002) in FSL Randomize (5000 permutations). Permuted $t$ statistics were corrected for multiple comparisons using cluster-based techniques (Maris and Oostenveld, 2007) with an initial cluster-forming 
Table 1. DCM parameter priors including the observation model, neuronal model, and experimental effects

\begin{tabular}{|c|c|c|c|}
\hline \multirow[b]{2}{*}{ Parameters } & \multicolumn{2}{|l|}{ Prior } & \multirow[b]{2}{*}{ Interpretation } \\
\hline & Mean $(\pi)$ & $\begin{array}{l}\text { Variance } \\
(\sigma)\end{array}$ & \\
\hline \multicolumn{4}{|l|}{ Observation model } \\
\hline$\alpha_{\mathrm{u}}$ & 0 & $1 / 16$ & Exogenous white input \\
\hline$\alpha_{\varsigma}$ & 0 & $1 / 16$ & Channel white noise \\
\hline$\beta_{u}$ & 0 & $1 / 16$ & Exogenous pink input \\
\hline$\beta_{\mathrm{s}}$ & 0 & $1 / 16$ & Channel pink noise \\
\hline$\theta$ & 1 & 1 & Lead-field gain \\
\hline [Deep, super, stellate] & {$[0.2,0.8,0.2]$} & {$[1 / 16]$} & [Subpopulation contributions] \\
\hline \multicolumn{4}{|l|}{ Neuronal sources } \\
\hline $1 / \kappa_{1}$ & $2 \mathrm{~ms}$ & $1 / 16$ & Time constant (s.s.) \\
\hline $1 / \kappa_{2}$ & $2 \mathrm{~ms}$ & $1 / 16$ & Time constant (s.p.) \\
\hline $1 / \kappa_{3}$ & $16 \mathrm{~ms}$ & $1 / 16$ & Time constant (i.i.) \\
\hline $1 / \kappa_{4}$ & $28 \mathrm{~ms}$ & $1 / 16$ & Time constant (d.p.) \\
\hline$\gamma_{1}$ & 4 & $1 / 16$ & Intrinsic connection (s.s. to >s.s.) \\
\hline$\gamma_{2}$ & 4 & $1 / 16$ & Intrinsic connection (s.p. to > s.s.) \\
\hline$\gamma_{3}$ & 4 & $1 / 16$ & Intrinsic connection (i.i. to >s.s.) \\
\hline$\gamma_{4}$ & 4 & $1 / 16$ & Intrinsic connection (i.i. to > i.i.) \\
\hline$\gamma_{5}$ & 4 & $1 / 16$ & Intrinsic connection (s.s. to >i.i.) \\
\hline$\gamma_{6}$ & 2 & $1 / 16$ & Intrinsic connection (d.p. to >i.i.) \\
\hline$\gamma_{7}$ & 4 & $1 / 16$ & Intrinsic connection (s.p. to >s.p.) \\
\hline$\gamma_{8}$ & 4 & $1 / 16$ & Intrinsic connection (s.s. to >s.p.) \\
\hline$\gamma_{9}$ & 2 & $1 / 16$ & Intrinsic connection (i.i. to > d.p.) \\
\hline$\gamma_{10}$ & 1 & $1 / 16$ & Intrinsic connection (d.p. to > d.p.) \\
\hline D & $1 \mathrm{~ms}$ & $1 / 16$ & Laminar delay \\
\hline \multicolumn{4}{|l|}{ Experimental design } \\
\hline$\beta_{1}$ & 0 & $1 / 8$ & Modulation of $\gamma_{1}$ \\
\hline$\beta_{2}$ & 0 & $1 / 8$ & Modulation of $\gamma_{7}$ \\
\hline$\beta_{3}$ & 0 & $1 / 8$ & Modulation of $\gamma_{4}$ \\
\hline$\beta_{4}$ & 0 & $1 / 8$ & Modulation of $\gamma_{10}$ \\
\hline
\end{tabular}

s.s., Spiny stellate; s.p., superficial pyramidal; i.i., inhibitory interneuron; d.p., deep pyramidal.

threshold of $t=2.3$. This approach allowed us to examine the temporal profile of oscillatory spectral modulations and, in the case of alpha activity, to study changes after $300 \mathrm{~ms}$ that were not confounded by the evoked response.

\section{Results}

Subjective effects

All participants reported marked changes in their normal conscious experience after psilocybin infusion. The most common effects included altered visual, spatial, and temporal perception; loosened associations; and vivified imagination. However, more profound effects such as depersonalization or "ego disintegration" were also scored highly by some participants. Expressed as a percentage, with $100 \%$ signaling "extremely intense effects," participants rated the subjective strength of their experience at $78.2 \%$ (SE, 5.5\%) 5 min after infusion of psilocybin, decreasing to $65.4 \%$ (SE, $4.7 \%$ ) after $15 \mathrm{~min}$; placebo had negligible effects (both time points, $0.7 \%$; SE, 2.5\%). Items rated 15 min postscanning are shown in Figure 2.

\section{Spectral analysis and source localization: spontaneous activity}

To localize corresponding spectral changes in cortical activity, we used the beamformer source localization technique SAM. Figure 3 displays the contrast of psilocybin after versus before infusion compared with placebo after versus before infusion. Results revealed decreased oscillatory power across a broad frequency range after psilocybin infusion, mainly localized to association cortices-with marked decreases in areas of the default-mode network (DMN; Raichle et al., 2001) such as the PCC. In posterior areas, the decreases were observed in the delta $(1-4 \mathrm{~Hz})$,
Table 2. Local maxima of source power changes (Talairach coordinates) corresponding to the images in Figure 1

\begin{tabular}{|c|c|c|c|c|}
\hline & \multicolumn{3}{|c|}{ Talairach coordinates } & \multirow[b]{2}{*}{$t$} \\
\hline & $x$ & $y$ & $z$ & \\
\hline \multicolumn{5}{|l|}{$\overline{\text { Delta }}$} \\
\hline Precuneus (R) & 25 & -63 & 31 & -8.14 \\
\hline Posterior cingulate gyrus (L) & -23 & -45 & 37 & -7.55 \\
\hline Insula (L) & -55 & -33 & 19 & -6.88 \\
\hline Precentral gyrus (L) & -39 & -19 & 35 & -6.38 \\
\hline Postcentral gyrus (R) & 55 & -11 & 53 & -5.08 \\
\hline Anterior cingulate gyrus (L) & -19 & 25 & 33 & -4.74 \\
\hline Postcentral gyrus (R) & 51 & -17 & 25 & -4.60 \\
\hline Superior frontal gyrus (L) & -15 & 11 & 53 & -4.50 \\
\hline \multicolumn{5}{|l|}{ Theta } \\
\hline Superior parietal lobule (R) & 29 & -57 & 61 & -6.24 \\
\hline Postcentral gyrus (L) & -27 & -37 & 51 & -5.42 \\
\hline Superior temporal gyrus (L) & -49 & -55 & 15 & -5.35 \\
\hline Superior parietal lobule (L) & -15 & -67 & 65 & -5.11 \\
\hline Precuneus (L) & -5 & -47 & 53 & -4.98 \\
\hline Paracentral lobule (L) & -5 & -41 & 77 & -4.83 \\
\hline Precentral gyrus (R) & 39 & -15 & 69 & -4.30 \\
\hline Supramarginal gyrus (R) & 53 & -47 & 31 & -4.19 \\
\hline \multicolumn{5}{|l|}{ Alpha } \\
\hline Superior parietal lobule (L) & -13 & -53 & 61 & -8.95 \\
\hline Precuneus (L) & -7 & -61 & 33 & -8.94 \\
\hline Supramarginal gyrus (R) & 59 & -43 & 29 & -8.65 \\
\hline Transverse temporal gyrus (L) & -55 & -19 & 11 & -8.11 \\
\hline Superior temporal gyrus (R) & 63 & -27 & 7 & -7.18 \\
\hline Insula (R) & 33 & -11 & 9 & -7.16 \\
\hline Supramarginal gyrus (L) & -51 & -51 & 25 & -6.68 \\
\hline Anterior cingulate gyrus (R) & 5 & 35 & 11 & -5.48 \\
\hline Inferior frontal gyrus $(\mathrm{L})$ & -55 & 21 & 21 & -5.33 \\
\hline Middle frontal gyrus (L) & -55 & 5 & 47 & -5.28 \\
\hline Cingulate gyrus (L) & -1 & 3 & 31 & -5.15 \\
\hline Middle frontal gyrus (L) & -21 & -1 & 45 & -5.07 \\
\hline Medial frontal gyrus (L) & -5 & -3 & 51 & -5.06 \\
\hline Middle frontal gyrus (R) & 29 & 9 & 57 & -4.70 \\
\hline \multicolumn{5}{|l|}{ Beta } \\
\hline Precuneus (R) & 25 & -53 & 33 & -9.15 \\
\hline Insula (L) & -43 & -19 & 15 & -7.73 \\
\hline Superior temporal gyrus (L) & -35 & -51 & 17 & -7.71 \\
\hline Medial frontal gyrus (L) & -21 & 27 & 23 & -6.87 \\
\hline Superior frontal gyrus (R) & 19 & 65 & 5 & -6.69 \\
\hline Superior Frontal gyrus (R) & 5 & 59 & 27 & -6.50 \\
\hline Superior parietal lobule (L) & -21 & -69 & 63 & -6.31 \\
\hline Inferior frontal gyrus (L) & -57 & 13 & 35 & -6.26 \\
\hline Postcentral gyrus (L) & -59 & -33 & 53 & -5.74 \\
\hline Superior frontal gyrus (R) & 17 & 17 & 65 & -4.83 \\
\hline \multicolumn{5}{|l|}{ Low gamma } \\
\hline Precentral gyrus (R) & 37 & -25 & 71 & -5.28 \\
\hline Superior parietal lobule (L) & -19 & -61 & 65 & -5.17 \\
\hline Precentral gyrus (L) & 35 & -7 & 69 & -5.04 \\
\hline Middle frontal gyrus (L) & -47 & 33 & 31 & -4.91 \\
\hline Superior frontal gyrus $(\mathrm{L})$ & -43 & 15 & 55 & -4.91 \\
\hline Postcentral gyrus (R) & 15 & -59 & 69 & -4.72 \\
\hline Middle frontal gyrus (L) & -23 & 15 & 57 & -4.71 \\
\hline Middle frontal gyrus (R) & 43 & 23 & 49 & -4.55 \\
\hline Superior parietal lobule (R) & 41 & -59 & 57 & -4.29 \\
\hline Precentral gyrus (L) & -55 & -19 & 37 & -4.28 \\
\hline \multicolumn{5}{|l|}{ High gamma } \\
\hline Middle frontal gyrus (L) & -43 & 15 & 57 & -3.22 \\
\hline Middle frontal gyrus (R) & 31 & 23 & 59 & -3.18 \\
\hline Superior frontal gyrus (R) & 23 & -1 & 71 & -2.89 \\
\hline Precentral gyrus (L) & -63 & -15 & 41 & -2.84 \\
\hline
\end{tabular}

$L$, Left; $R$, right.

theta $(48 \mathrm{~Hz})$, alpha $(8-13 \mathrm{~Hz})$, beta $(13-30 \mathrm{~Hz})$, and low gamma $(30-50 \mathrm{~Hz})$ frequency bands. In bilateral prefrontal cortices, the decreased power ("desynchronization") ranged from alpha $(8-13 \mathrm{~Hz})$ to high gamma $(50-100 \mathrm{~Hz})$. The result of simple 


\section{Subjective effects of psilocybin}

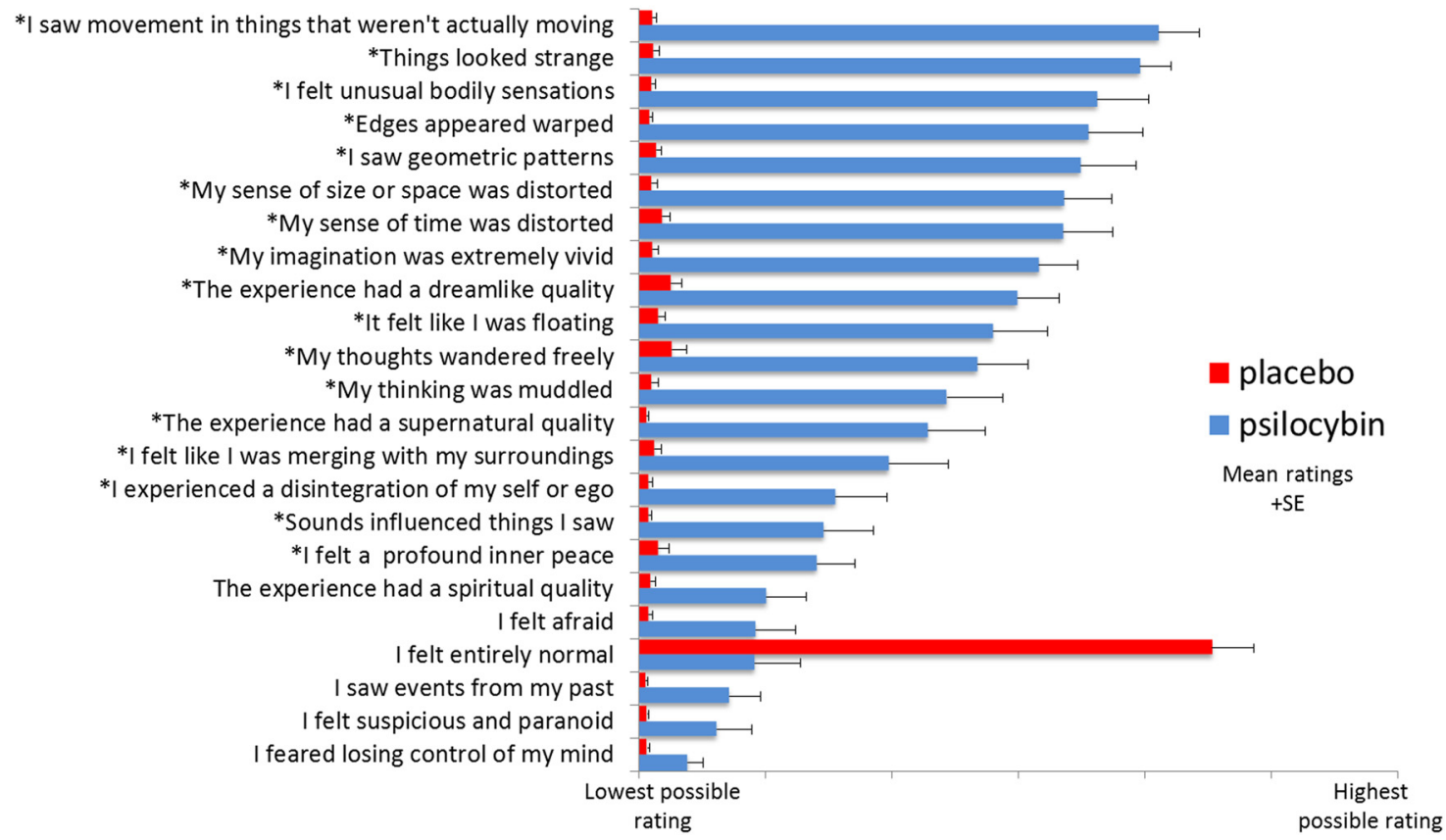

Figure 2. Ratings of psychometric scale items performed within 15 min of participants exiting the scanner after both sessions. Items were completed using a visual analog scale format, with a bottom anchor of "no, not more than usually" and a top anchor of "yes, much more than usually" for every item, with the exception of "I felt entirely normal," which had bottom and top anchors of "No, l experienced a different state altogether" and "Yes, I felt just as I normally do," respectively. Shown are the mean ratings for 15 participants plus the positive SEMs. All items marked with an asterisk were scored significantly higher after psilocybin than placebo infusion at a Bonferroni-corrected significance level of $p<0.0022$ (0.5/23 items).
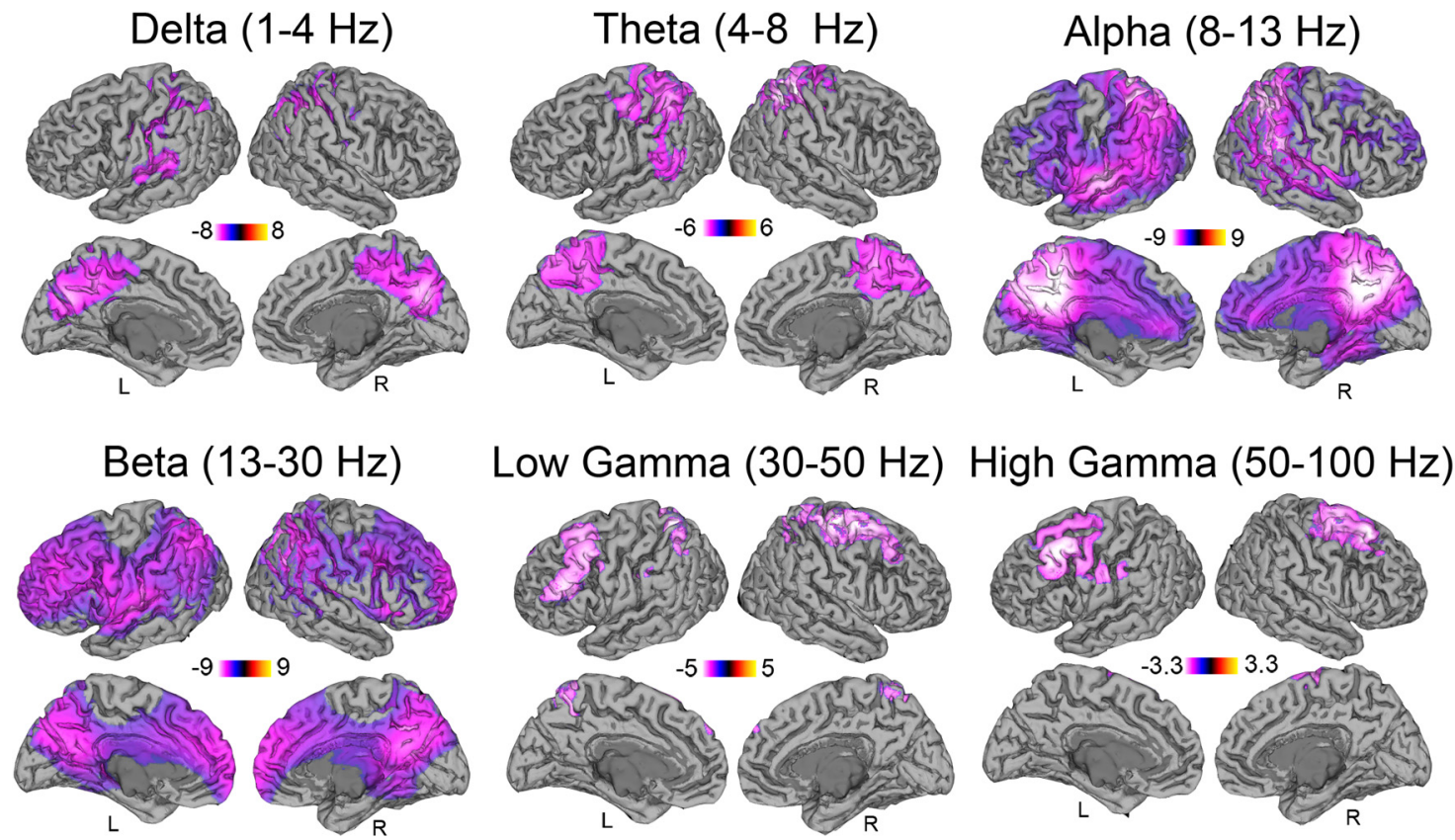

Figure 3. Statistical parametric maps showing the locations of significant $(p<0.05$, corrected) changes in source oscillatory power. Contrasts of spectral power represent the difference of psilocybin after and before infusion versus placebo after and before infusion. All significant changes are decreases in spectral power after psilocybin infusion in the six frequency bands that span from 1 to $100 \mathrm{~Hz}$. L, Left; R, right.

contrasts between after and before psilocybin infusion showed very similar spatial localizations and direction of effect compare with those of the interaction contrast in Figure 3 (i.e., decreased power). No increases in oscillatory power were observed in any region. As such, the interaction effects in Figure 3 can be inter- preted as a decrease of power following administration of psilocybin. A comparison of head position from the beginning to the end of the resting MEG recordings showed no significant difference in movement between psilocybin and placebo sessions $(t=$ $0.63, p=0.53)$. 


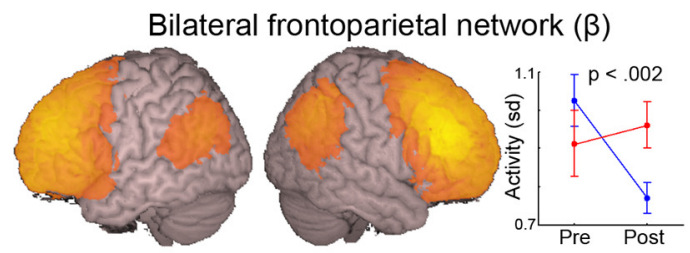

Bilateral motor network $(\beta)$
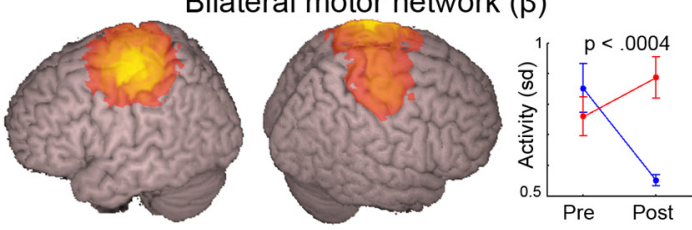

Bilateral parietal network $(\beta)$
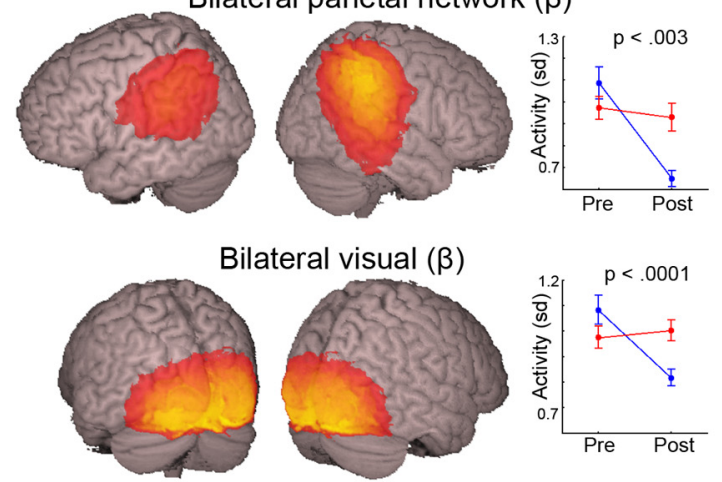

Bilateral visual $(\beta)$
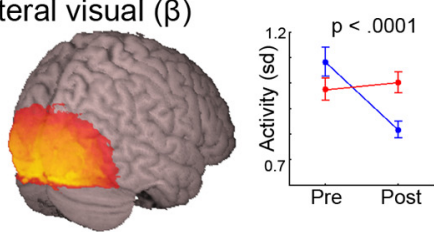

Bilateral fronto-temporoparietal network $(\bar{\delta})$
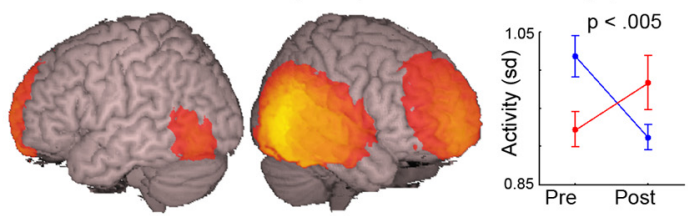

Bilateral middle temporal $(\alpha)$
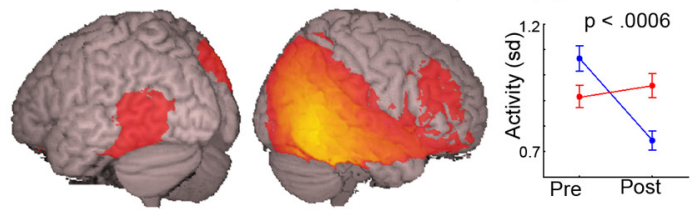

Bilateral parietotemporal $(\theta)$
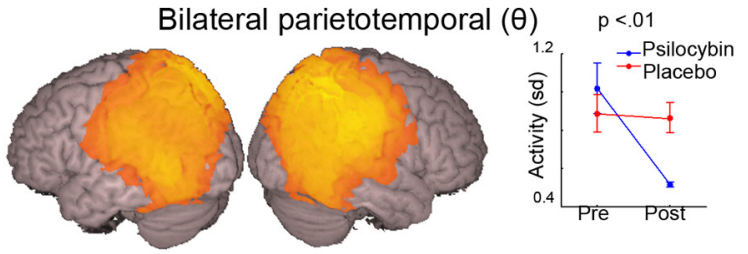

Figure 4. The estimated spatial distribution of seven resting-state networks that were significantly modulated $(p<0.01)$ by psilocybin. Network structures are superimposed onto the MNI template brain. These independent components were thresholded at 0.2 , and the frequency band used to derive each map is indicated by the relevant Greek letter. The right-hand graphs show the SD of the temporal expression of each independent component for both the placebo and psilocybin conditions. This can be interpreted as a measure of activity in the relevant frequency band for the relevant network. The $p$ value reflects the interaction term in a $2 \times 2$ repeated-measures ANOVA. Pre, Before; Post, after.

\section{Resting-state MEG networks}

Techniques have recently been developed to identify spatiotemporally coherent brain networks in MEG data using independent component analysis (Brookes et al., 2011). Applying this to our resting-state data, we recovered 11 functional brain networks, 7 of which showed post-psilocybin infusion decreases in oscillatory power in the frequency bands from which they were derived $(p<$ 0.01, uncorrected; Fig. 4). A further four networks were identified that did not pass the significance criterion. These networks were a bilateral parietal network in the delta band $(p=0.065)$, a bilateral extrastriate cortex network in the alpha band $(p=0.061)$, a bilateral frontal cortex network in the low gamma band $(p=$ 0.013 ), and a bilateral extrastriate cortex network in the high gamma band ( $p=0.057$ ). Despite not reaching significance, activity in these four networks was consistently decreased under the effects of psilocybin.

\section{Dynamic causal modeling}

Recently, mathematical modeling techniques have been developed to test hypotheses about the underlying cell populations responsible for steady-state changes in spectral power recorded with EEG and MEG, termed DCM for steady-state responses (Moran et al., 2009). Thus, to identify the most likely synaptic mechanism underlying the psilocybin-induced desynchronization, we constructed a model based on the canonical microcircuit thought to recapitulate the intrinsic circuitry of individual cortical regions (Bastos et al., 2012). This model encompasses four cell types and their respective connections (Fig. 5b). We used the beamformer to estimate spectral activity in the PCC, which was significantly decreased in the alpha band after psilocybin infusion
(Fig. 5a). We set up a model where drug effects could be accounted for by differential gain (or excitability) of each of the four cell types ( $\beta$ parameters; Fig. $5 b$ ). Paired $t$ tests using a Bonferroni-adjusted significance level of $p=0.0125(0.05 / 4$ parameters) showed a psilocybin-dependent increase in the excitability of deep-layer pyramidal cells (Fig. 5c). These modeling results in humans are consistent with the results of the animal studies that directly recorded $5-\mathrm{HT}_{2 \mathrm{~A}}$ receptor-mediated increases in EPSPs in layer 5 pyramidal cells (Andrade, 2011). Moreover, excitation of deep-layer pyramidal cells is consistent with decreased brain activity (Carhart-Harris et al., 2012a) and oscillatory power because the net effect of feedback connections is thought to be inhibitory (Bastos et al., 2012). Individual data and model fits for each participant are presented in Figure 6.

\section{Visually induced and motor-induced gamma oscillations}

Psilocybin had a profound effect on participants' subjective state, as reflected in the marked changes in spontaneous brain activity. When asked to perform a simple visuomotor task, participants performed reasonably well, being marginally slower $(t=2.56$, $p=0.023)$ after psilocybin ( $295 \mathrm{~ms} ; \mathrm{SE}, 15 \mathrm{~ms})$ than placebo $(260$ $\mathrm{ms}$; SE, $22 \mathrm{~ms}$ ) infusion. Analyses of EMG onset time-locked spectral responses are presented in Figure 7. Time-frequency responses (Fig. 7b) show the typical component morphology seen during simple movement tasks. This morphology includes a short-lasting burst of gamma-band activity accompanied by a desynchronization, and later rebound of the beta rhythm (Jurkiewicz et al., 2006; Cheyne et al., 2008). No significant differences were seen between placebo and psilocybin for either the gamma $(60-90 \mathrm{~Hz})$ or beta $(15-30 \mathrm{~Hz})$ band. For the motor cortex 

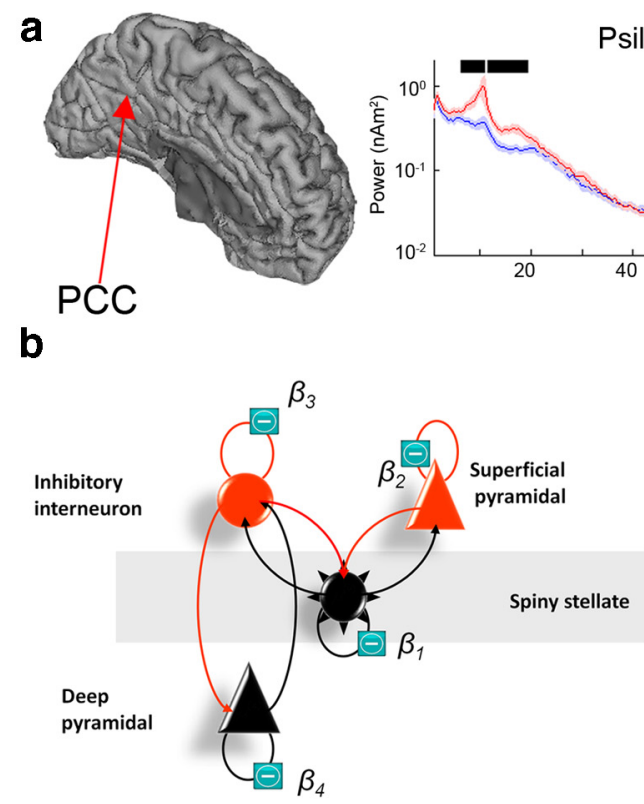

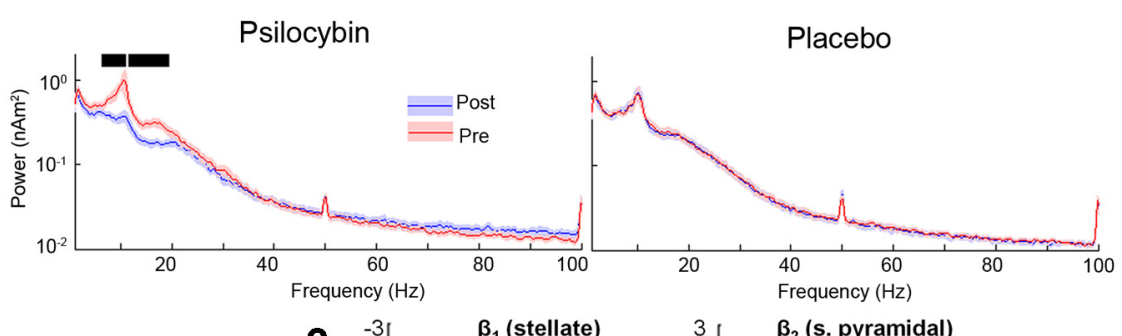

c

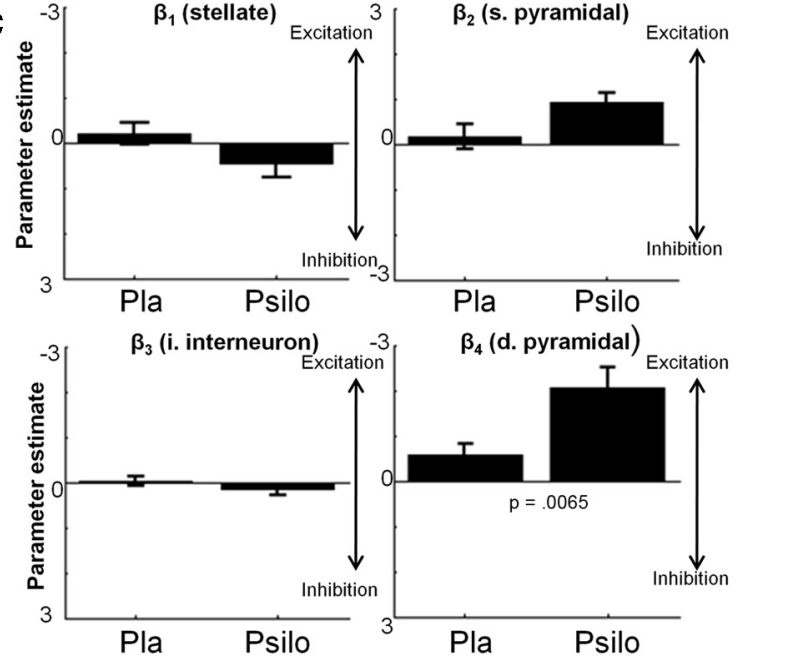

Figure 5. a, Power spectra for reconstructed source data from the PCC. Data are presented for both psilocybin (Psilo) and placebo (Pla) sessions both before (Pre) and after infusion (Post). The black bars represent areas where $2 \times 2$ repeated-measures ANOVA revealed an interaction effect in the frequency spectra $(p<0.05$, corrected). $\boldsymbol{b}$, Schematic representation of the neural mass model (the canonical cortical microcircuit) used to predict spectral activity. The model consists of four cell types with 10 connectivity parameters $\left(\gamma_{1 \ldots 10}\right)$. Four parameters $\left(\beta_{1,2,3,4}\right)$ encoding gain were allowed to vary between presessions and postsessions. These four parameters allow the gain of the four cell types to differ between Pre and Post. Data fitted were the source-modeled spectral response of the PCC. $c$, The parameter estimates for the four cell types for both psilocybin and placebo. The only parameter that was significantly altered (placebo versus psilocybin) was the $\beta_{4}$ parameter $(t=3.23, p=0.0065)$, using a paired $t$ test over subjects. Note: the Bonferonni-adjusted significance level of $p=0.0125(0.05 / 4)$ for these tests. The direction of effect indicated that the obtained spectral responses were best modeled by increased excitability of the deep pyramidal cell population. All individual data and model fits can be found in Figure 6 . The results for all $\beta$ parameters were as follows: $\beta_{1}(t=-1.86, p=0.085) ; \beta_{2}(t=-2.31, p=0.03) ; \beta_{3}(t=-1.11, p=0.028) ;$ and $\beta_{4}(t=-3.23, p=0.0065)$. Hence, only $\beta_{4}$ survived multiple-comparison correction.

source locations, we repeated the time-frequency analysis with no baseline correction (raw source amplitude estimates) applied to examine the baseline spectra in the frequency windows of interest for each task. For the motor cortex virtual sensors, no significant differences were seen in the prestimulus baseline in either the gamma $(t=0.60, p=0.56)$ or beta $(t=1.69, p=0.11)$ frequency bands.

Analyses of visual cortical responses time locked to stimulus onset are presented in Figure 8. The time-frequency response plots show the typical component morphology seen during visual stimulation with a grating patch. This morphology includes a short-lasting burst of broadband gamma-band activity accompanied by a long-duration gamma response, together with alpha desynchronization. No significant differences were seen in either the gamma $(35-80 \mathrm{~Hz})$ or alpha $(8-13 \mathrm{~Hz})$ band. For the virtual sensors from the visual cortex, no difference in baseline gammaband activity was seen $(t=-0.23, p=0.82)$. There were baseline alpha power differences $(t=4.02, p=0.0015)$. This is consistent with the resting-state analysis and might account for the tendency for the slight (nonsignificant) reduction in alpha desynchronization seen during visual stimulation. Together, the analyses in Figures 7 and 8 suggest that some low-level induced elements of oscillatory brain activity are relatively preserved during the psychedelic experience. A comparison of head position from the beginning to the end of the task-related MEG recordings showed no significant difference in movement between psilocybin and placebo sessions $(t=1.23, p=0.23)$.

\section{Psychometric correlations}

We conducted exploratory correlations between resting postpsilocybin infusion changes (decreases) in alpha power extracted from a PCC mask for each participant versus the visual analog scale-style items rated after the experience (Fig. 1). Analyses were restricted to the alpha frequency band to minimize multiple testing and because the PCC alpha-power decreases were especially marked (Fig. 3). There were strong ceiling and floor effects for the highest and lowest rated items in the 23-item rating scale (Fig. 1), thus making meaningful correlations with these items unlikely. However, scores for other items were more broadly distributed. Using a Bonferroni-adjusted significance level of $p=0.0022$ (0.05/23 items), two items showed positive significant correlations with PCC alpha-power decreases. These were, "I experienced a disintegration of my 'self or 'ego"' $\left(R^{2}=0.66, p=0.00016\right)$ and "the experience had a supernatural quality" $\left(R^{2}=0.53, p=0.00018\right)$. Positive correlations were also found between deep-layer pyramidal cell excitation and the magnitude of the decreases in PCC alpha power $\left(R^{2}=0.42, p=0.0056\right)$ and ratings of ego disintegration $\left(R^{2}\right.$ $=0.42, p=0.005)$. The psychometric correlations presented in this section will require subsequent replication given their exploratory nature.

\section{Discussion}

The present study examined the neural effects of a classic psychedelic drug using MEG. We observed a broadband desynchronization of cortical oscillatory rhythms after psilocybin infusion 

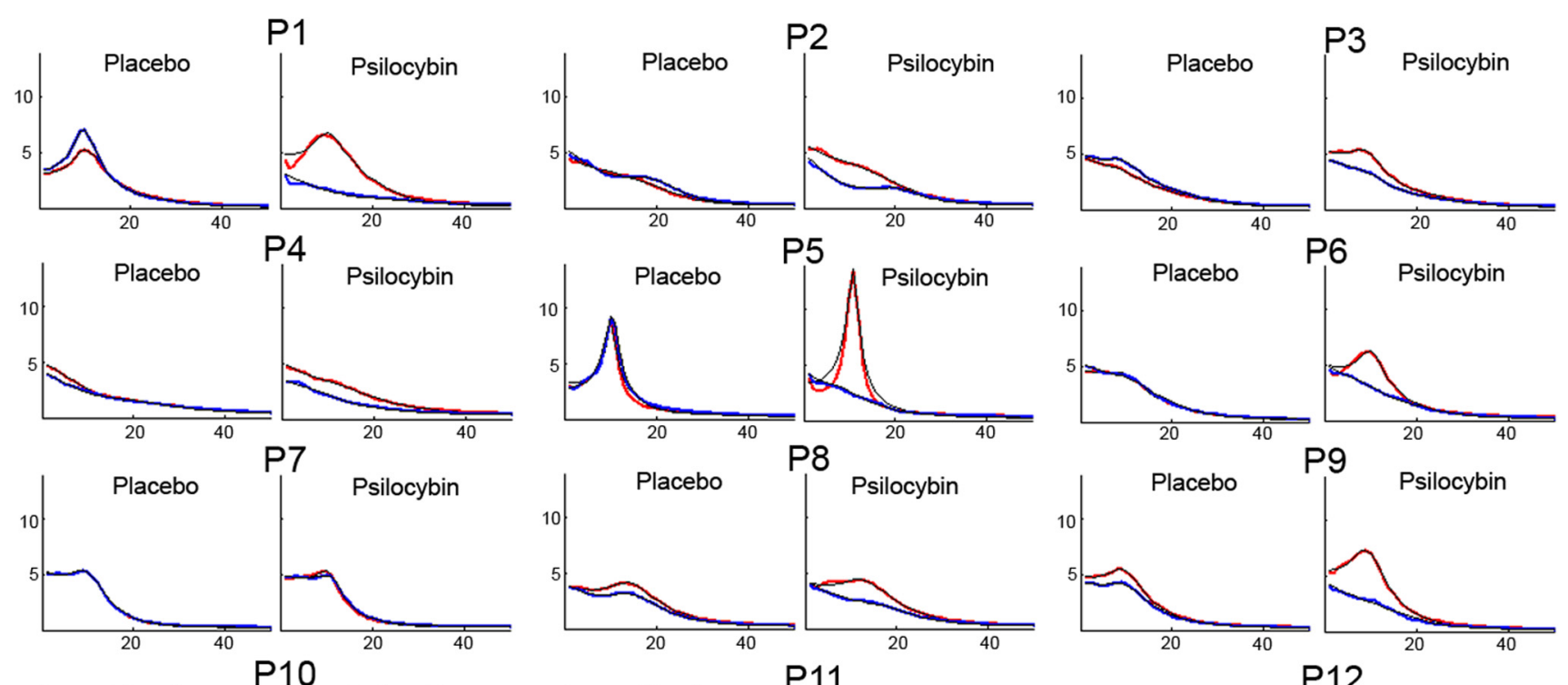

P9
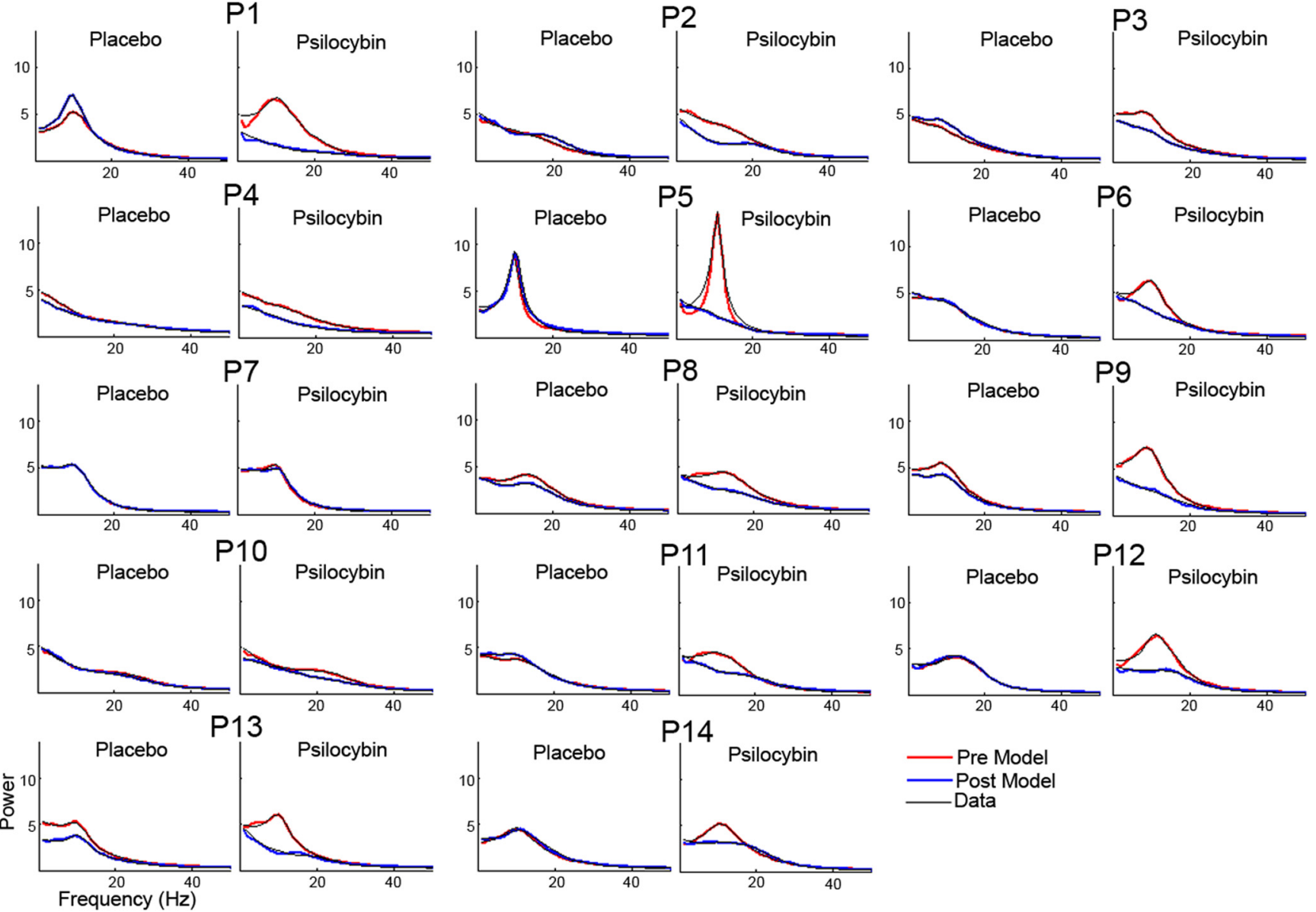

Figure 6. Single-participant [participant 1 (P1) to P14] DCM model fits for source-level power spectra for prerecordings and postrecordings following placebo and psilocybin infusion for reconstructed PCC activity. Model-estimated spectra for Pre are in red and Post are in blue, and are overlaid on the data in black. DCM models were fitted from the range 1-100 $\mathrm{Hz}$ but are plotted here only up to $50 \mathrm{~Hz}$ for better visualization of alpha peaks.

and decreased brain network integrity. The results are consistent with those of previous EEG (Riba et al., 2004) and fMRI studies (Carhart-Harris et al., 2012a) in humans and electrophysiological recordings in animals (Wood et al., 2012), and they significantly extend our understanding of the mechanisms by which psychedelics alter oscillatory brain activity. By exploring the neuronal source of the decreases in oscillatory power with dynamic causal modeling, we present a model of the mechanism of action of psychedelics in the PCC. This begins at the cellular level with excitation of layer 5 pyramidal neurons, and extends to the macroscopic level with cortical desynchronization and decreased brain network integrity. We postulate that this excitation occurs via stimulation of $5-\mathrm{HT}_{2 \mathrm{~A}}$ receptors, which are densely expressed there (Erritzoe et al., 2009).

Previous pharmacological EEG and MEG studies have found increases and decreases in oscillatory power in different frequency bands post-drug infusion (Fink, 1969, 2010). That the decreases here occurred in all of the frequency bands implies a general collapse of the normal rhythmic structure of cortical activity. This supports the claim that psychedelics decrease, or, more accurately, disorganize, spontaneous brain activity (Carhart-Harris et al., 2012a). Moreover, the selective localization of the decreases to association cortices is consistent with previous fMRI work (Carhart-Harris et al., 2012a) and suggests that the reduced blood flow reported therein may relate to desynchronized neural activity. Indeed, the MEG source localization results we find here are highly consistent with previous fMRI results using the same pharmacological intervention (CarhartHarris et al., 2012a). Some of the key areas of overlap include the PCC, precuneus, superior and middle frontal gyri, anterior cingulate gyri, and supramarginal and precentral gyri. These mostly represent hub areas of association cortex rather than primary sensory cortex. The PCC showed especially marked effects in both studies, and these correlated with the drug's subjective effects (e.g., note the highly significant correlation between PCC alpha decreases and ratings of ego disturbance observed here). It is significant also that the spatial location of the effects observed with $\mathrm{AMRI}$ and MEG are consistent with the known distribution of 5- $\mathrm{HT}_{2 \mathrm{~A}}$ receptors. Explicitly, in a PET study of 5- $\mathrm{HT}_{2 \mathrm{~A}}$ receptor binding using ${ }^{18} \mathrm{~F}$-altanserin in 136 participants, association cortices had the highest binding potentials, and the PCC was highest of all (Erritzoe et al., 2009). The posterior association cortices showed desynchonization in a lower frequency range $(1-50 \mathrm{~Hz})$, whereas frontal association cortices showed higher frequency changes $(8-100 \mathrm{~Hz})$. These frequency differences may reflect the different resting rhythms that these areas spontaneously generate (Buzsaki, 2006). It is important not to overinterpret the specificity of MEG source localization data, as these data have inferior spatial resolution compared with both fMRI and PET. We did note, in some single-participant data, strong highfrequency desynchronizations in posterior association areas. However, these were quite inconsistent across both individuals 
and cortical locations, and did not survive at the group-level analysis. Further investigations will be needed to explain these individual differences in observed neural responses to psychedelic drugs.

A number of previous studies have investigated the relationship between blood flow metrics and oscillatory activity. These have generally found an inverse relationship between BOLD activity and alpha/beta rhythms (Goldman et al., 2002; Singh et al., 2002; Laufs et al., 2003; Scheeringa et al., 2011), while a positive relationship is found between gamma-band activity and BOLD activity (Logothetis et al., 2001; Scheeringa et al., 2011). With psilocybin, however, we observe a decrease in BOLD activity and a general decrease in oscillatory activity during resting-state conditions. The hypercapnic challenge delivered by Carhart-Harris et al. (2012a) suggests that the BOLD decreases seen in that study were not a confound of psilocybin working directly on the cerebral vasculature. Consistent with our human data, administration of the relatively selective $5-\mathrm{HT}_{2 \mathrm{~A}}$ receptor agonist DOI in rats resulted in dose-dependent decreases in broadband (including high-frequencies) oscillatory power and multiunit activity in the orbitofrontal and anterior cingulate cortices (Wood et al., 2012). This suggests a generalized reduction in neural activity (at least in terms of oscillations and hemodynamics) with $5-\mathrm{HT}_{2 \mathrm{~A}}$ receptor activation and a decoupling of the usual relationship between BOLD and neural oscillations.

In the present study, some of the largest decreases in oscillatory power were found in areas of the DMN (Fig. 3) consistent with recent fMRI studies revealing decreased blood flow in these regions after psilocybin infusion (Carhart-Harris et al., 2012a). The DMN consumes more energy (Raichle and Snyder, 2007), receives more perfusion (Zou et al., 2009), and is more widely connected (Hagmann et al., 2008) than other cortical regions. It undergoes significant ontogenetic development (Supekar et al., 2010) and underwent significant evolutionary expansion (Van Essen and Dierker, 2007), and its connectivity has been found to relate to personality (Adelstein et al., 2011) and psychopathology (Whitfield-Gabrieli and Ford, 2012). Several recent intracranial studies (Jerbi et al., 2010; Ossandón et al., 2011) have demonstrated that broadband, high-frequency, task-related suppression of DMN areas correlates with improved task performance. In these studies (Ossandón et al., 2011), during task performance, activity in task-positive networks emerges, whereas in the psychedelic state studied here a pharmacologically a

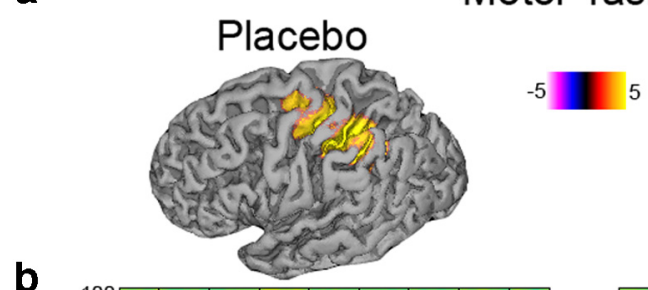

\section{Motor Task}

b
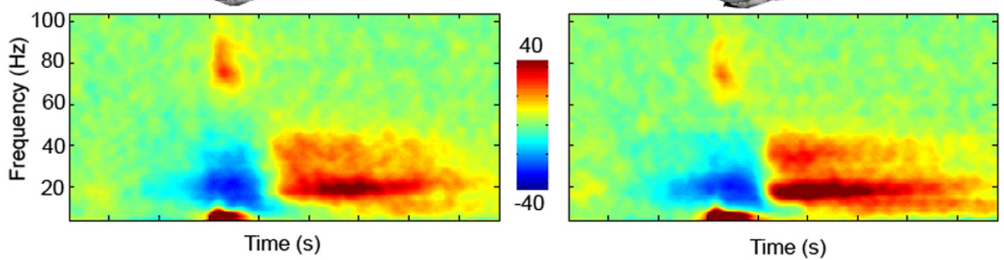

C
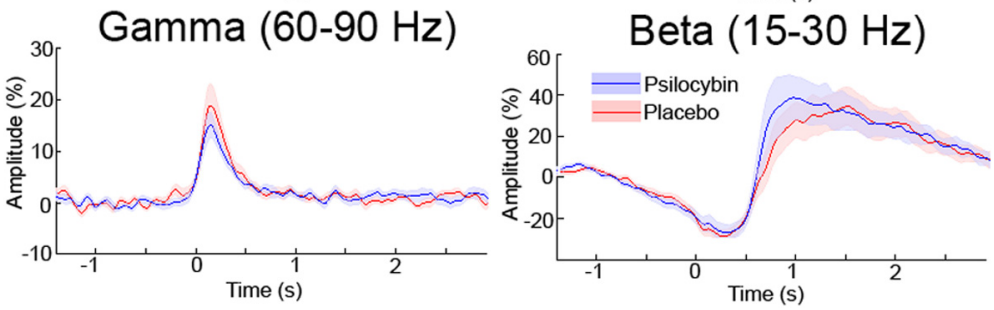

Figure 7. $\quad \boldsymbol{a}$, Grand-averaged source activity for movement-related gamma $(60-90 \mathrm{~Hz})$ activity $(p<0.05$, corrected) following administration of either placebo or psilocybin. The grand-averaged peak source location for each was located in Brodmann area 4. $\boldsymbol{b}$, Grand-averaged time-frequency spectrograms showing source-level oscillatory amplitude changes following index finger movement (movement onset at time $=0$ ). Spectrograms are displayed as the percentage change from the prestimulus baseline and were computed for frequencies up to $150 \mathrm{~Hz}$, but are truncated here to $100 \mathrm{~Hz}$ for visualization purposes. c, Envelopes of oscillatory amplitude for the gamma $(60-90 \mathrm{~Hz})$ and beta $(15-30 \mathrm{~Hz})$ bands, respectively. No significant differences were seen between placebo and psilocybin for these envelopes.

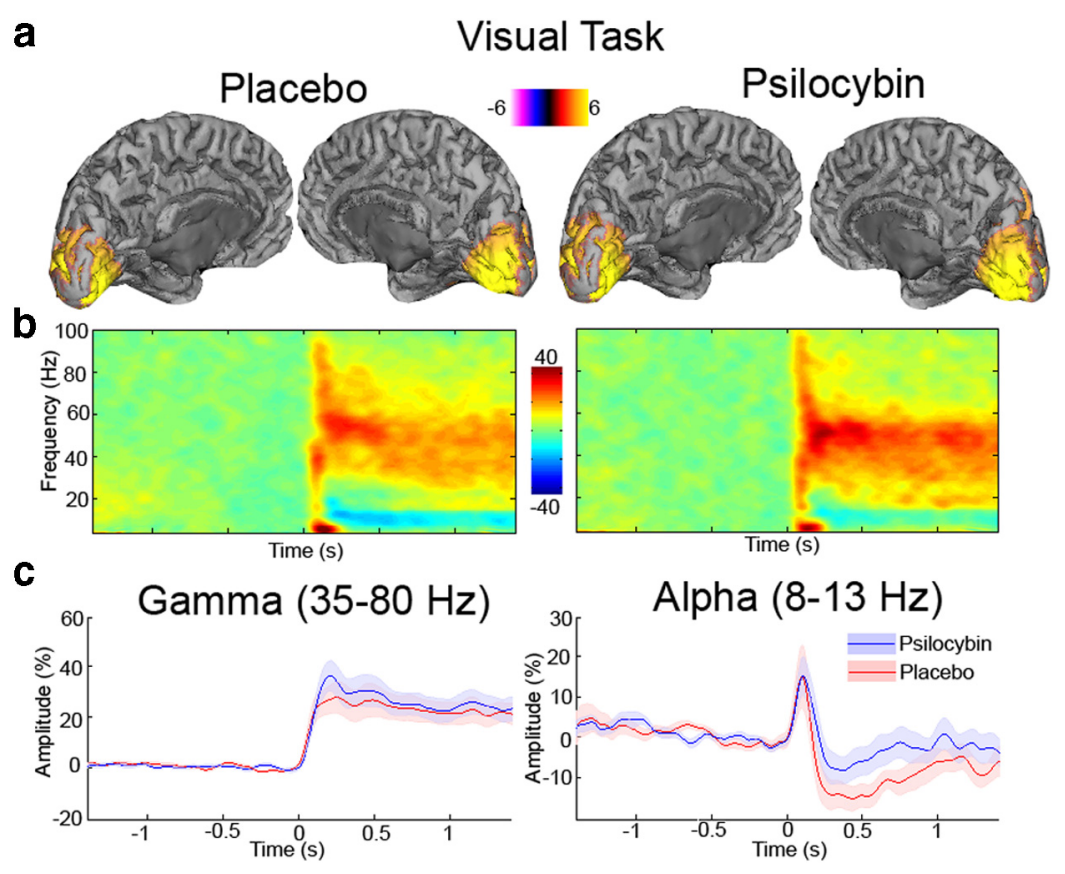

Figure 8. $\boldsymbol{a}$, Grand-averaged source activity for visual gamma $(35-80 \mathrm{~Hz})$ activity $(p<0.05$, corrected) following administration of either placebo or psilocybin. For each, the grand-averaged peak source location for each was located in pericalcarine cortex. $\boldsymbol{b}$, Grand-averaged time-frequency spectrograms showing source-level oscillatory amplitude changes following visual stimulation with a grating patch (stimulus onset at time $=0$ ) following administration of either placebo or psilocybin. Spectrograms are displayed as the percentage change from the prestimulus baseline and were computed for frequencies up to $150 \mathrm{~Hz}$, but are truncated here to $100 \mathrm{~Hz}$ for visualization purposes. $c$, Envelopes of oscillatory amplitude for the gamma $(35-80 \mathrm{~Hz})$ and alpha $(8-13 \mathrm{~Hz})$ bands, respectively. Although there was a tendency for slightly reduced alpha desynchronization with psilocybin, this was not statistically significant. 
driven suppression of all observed networks was seen, suggesting a general disorganization of network-level brain activity during resting conditions.

Psilocin is a mixed serotonin receptor agonist (Halberstadt and Geyer, 2011). However, the potency of psychedelics correlates positively with their affinity for the $5-\mathrm{HT}_{2 \mathrm{~A}}$ receptor (Glennon et al., 1984), and pretreatment with the $5-\mathrm{HT}_{2 \mathrm{~A}}$ receptor antagonist ketanserin blocks the hallucinogenic effects of psilocybin in humans (Vollenweider et al., 1998). 5- $\mathrm{HT}_{2 \mathrm{~A}}$ receptors are densely expressed in cortical regions (Erritzoe et al., 2009), particularly in cortical layer 5 (Weber and Andrade, 2010). The present modeling results, indicating increased excitation of deeplayer pyramidal cells, are entirely consistent with previous research. Stimulation of the $5-\mathrm{HT}_{2 \mathrm{~A}}$ receptor has been shown to enhance spontaneous EPSPs/EPSCs in neocortical layer 5 pyramidal cells by reducing outward potassium currents (Aghajanian and Marek, 1997; Lambe et al., 2000) and to cause increased glutamatergic recurrent activity in layer 5 of the cortex (Béïque et al., 2007). It is noteworthy that, while the decreases in spectral power seen here were broad, decreases in the alpha frequency were especially marked-particularly in the PCC where $5-\mathrm{HT}_{2 \mathrm{~A}}$ receptors are densely expressed (Erritzoe et al., 2009). Layer 5 pyramidal cells fire with an intrinsic alpha rhythm (Silva et al., 1991; Sun and Dan, 2009) and spontaneous alpha oscillations are closely linked to perceptual processing, including processing of space and time (Lorincz et al., 2009; Klimesch, 2012). Thus, the marked decreases in alpha power observed here with psilocybin were likely due to interference with the intrinsic alpha oscillations of deep-layer pyramidal neurons via stimulation of $5-\mathrm{HT}_{2 \mathrm{~A}}$ receptors, although we observed marked changes in spontaneous brain activity after psilocybin, but no effects on low-level induced gamma-band responses.

There are some limitations to the present work. Participants all had previous experience with psychedelic drugs. This was to minimize the risk of adverse responses by excluding volunteers who had a history of reacting negatively to psychedelics. However, that we used experienced participants limits the generalizability of the present results to psychedelic-naive individuals. Also, we used a fixed-order scanning protocol to avoid contaminating the placebo condition with subacute drug effects. A balanced-order design with a prolonged period between scans may be an alternative experimental design, although it would be difficult to perform in practice. However, we suggest that any potential order effects would likely be subtle relative to the marked neuronal and subjective effects of psilocybin. Reinforcing this view, in our previous fMRI work with psilocybin, similar results were observed with balanced (BOLD) and fixed (ASL) order scanning (Carhart-Harris et al., 2012a). This was also a single-blind design. However, in experiments such as this, comparing the acute effects of potent psychoactive drugs with those of a (necessarily) inert placebo, participants quickly become "unblinded" to the experimental manipulation, thus diminishing the value of blinding. Finally, it was necessary to remove periods of MEG data that were contaminated by large-muscle artifacts/head movements in the preprocessing stage. If these artifacts were correlated with particular aspects of the psychedelic state, then this (necessary) preprocessing step precluded their detection.

Previous theoretical accounts of positive psychotic symptoms suggest that delusional thinking represents a failure of neural mechanisms to accurately encode predictions and prediction error or "surprise" (Corlett et al., 2010). In one prediction-coding model of global brain function based on the free-energy principle (Friston, 2010), activity in deep-layer projection neurons en- codes top-down inferences about the world. Speculatively, if deep-layer pyramidal cells were to become hyperexcitable during the psychedelic state, information processing would be biased in the direction of inference-such that implicit models of the world become spontaneously manifest-intruding into consciousness without prior invitation from sensory data. This could explain many of the subjective effects of psychedelics.

Finally, the therapeutic potential of psychedelics is currently attracting much interest (Grob et al., 2011; Krebs and Johansen, 2012). Frontoparietal connectivity has been found to correlate with rumination in depression (Berman et al., 2011), and deficient $5-\mathrm{HT}_{2 \mathrm{~A}}$ receptor stimulation have been found to be associated with trait neuroticism (Frokjaer et al., 2008) and pessimism (Meyer et al., 2003). Here we found decreased frontoparietal connectivity after psilocybin infusion, consistent with previous fMRI findings (Carhart-Harris et al., 2012a). Thus, the ability of serotonergic psychedelics to disrupt pathological patterns of brain activity via stimulation of $5-\mathrm{HT}_{2 \mathrm{~A}}$ receptors may underlie their therapeutic potential in psychiatric settings (Grob et al., 2011; Krebs and Johansen, 2012), and breakdown of brain networks may be a fundamental feature of the psychedelic state.

\section{References}

Adelstein JS, Shehzad Z, Mennes M, Deyoung CG, Zuo XN, Kelly C, Margulies DS, Bloomfield A, Gray JR, Castellanos FX, Milham MP (2011) Personality is reflected in the brain's intrinsic functional architecture. PLoS One 6:e27633. CrossRef Medline

Adjamian P, Holliday IE, Barnes GR, Hillebrand A, Hadjipapas A, Singh KD (2004) Induced visual illusions and gamma oscillations in human primary visual cortex. Eur J Neurosci 20:587-592. CrossRef Medline

Aghajanian GK, Marek GJ (1997) Serotonin induces excitatory postsynaptic potentials in apical dendrites of neocortical pyramidal cells. Neuropharmacology 36:589-599. CrossRef Medline

Andrade R (2011) Serotonergic regulation of neuronal excitability in the prefrontal cortex. Neuropharmacology 61:382-386. CrossRef Medline

Bardouille T, Picton TW, Ross B (2006) Correlates of eye blinking as determined by synthetic aperture magnetometry. Clin Neurophysiol 117:952958. CrossRef Medline

Bastos AM, Usrey WM, Adams RA, Mangun GR, Fries P, Friston KJ (2012) Canonical microcircuits for predictive coding. Neuron 76:695-711. CrossRef Medline

Béique JC, Imad M, Mladenovic L, Gingrich JA, Andrade R (2007) Mechanism of the 5-hydroxytryptamine $2 \mathrm{~A}$ receptor-mediated facilitation of synaptic activity in prefrontal cortex. Proc Natl Acad Sci U S A 104:98709875. CrossRef Medline

Berman MG, Peltier S, Nee DE, Kross E, Deldin PJ, Jonides J (2011) Depression, rumination and the default network. Soc Cogn Affect Neurosci 6:548-555. CrossRef Medline

Brainard DH (1997) The psychophysics toolbox. Spat Vis 10:433-436. CrossRef Medline

Brookes MJ, Gibson AM, Hall SD, Furlong PL, Barnes GR, Hillebrand A, Singh KD, Holliday IE, Francis ST, Morris PG (2005) GLMbeamformer method demonstrates stationary field, alpha ERD and gamma ERS co-localisation with fMRI BOLD response in visual cortex. Neuroimage 26:302-308. CrossRef Medline

Brookes MJ, Woolrich M, Luckhoo H, Price D, Hale JR, Stephenson MC, Barnes GR, Smith SM, Morris PG (2011) Investigating the electrophysiological basis of resting state networks using magnetoencephalography. Proc Natl Acad Sci U S A 108:16783-16788. CrossRef Medline

Buzsaki, G. (2006) Rhythms of the brain. Oxford: Oxford UP.

Carhart-Harris RL, Williams TM, Sessa B, Tyacke RJ, Rich AS, Feilding A, Nutt DJ (2011) The administration of psilocybin to healthy, hallucinogen-experienced volunteers in a mock-functional magnetic resonance imaging environment: a preliminary investigation of tolerability. J Psychopharmacol 25:1562-1567. CrossRef Medline

Carhart-Harris RL, Erritzoe D, Williams T, Stone JM, Reed LJ, Colasanti A, Tyacke RJ, Leech R, Malizia AL, Murphy K, Hobden P, Evans J, Feilding A, Wise RG, Nutt DJ (2012a) Neural correlates of the psychedelic state 
as determined by fMRI studies with psilocybin. Proc Natl Acad Sci U S A 109:2138-2143. CrossRef Medline

Carhart-Harris RL, Leech R, Erritzoe D, Williams TM, Stone JM, Evans J, Sharp DJ, Feilding A, Wise RG, Nutt DJ (2012b) Functional connectivity measures after psilocybin inform a novel hypothesis of early psychosis. Schizophr Bull. Advance online publication. Retrieved August 21, 2013. doi:10.1093/schbul/sbs117. CrossRef Medline

Carl C, Açik A, König P, Engel AK, Hipp JF (2012) The saccadic spike artifact in MEG. Neuroimage 59:1657-1667. CrossRef Medline

Chau W, McIntosh AR, Robinson SE, Schulz M, Pantev C (2004) Improving permutation test power for group analysis spatically filtered MEG data. Neuroimage 23:983-996. CrossRef Medline

Cheyne D, Bostan AC, Gaetz W, Pang EW (2007) Event-related beamforming: a robust method for presurgical functional mapping using MEG. Clin Neurophysiol 118:1691-1704. CrossRef Medline

Cheyne D, Bells S, Ferrari P, Gaetz W, Bostan AC (2008) Self-paced movements induce high-frequency gamma oscillations in primary motor cortex. Neuroimage 42:332-342. CrossRef Medline

Corlett PR, Taylor JR, Wang XJ, Fletcher PC, Krystal JH (2010) Toward a neurobiology of delusions. Prog Neurobiol 92:345-369. CrossRef Medline

Dittrich A (1998) The standardized psychometric assessment of altered states of consciousness (ASCs) in humans. Pharmacopsychiatry 31 [Suppl 2]: 80-84. CrossRef Medline

Erritzoe D, Frokjaer VG, Haugbol S, Marner L, Svarer C, Holst K, Baaré WF, Rasmussen PM, Madsen J, Paulson OB, Knudsen GM (2009) Brain serotonin $2 \mathrm{~A}$ receptor binding: relations to body mass index, tobacco and alcohol use. Neuroimage 46:23-30. CrossRef Medline

Fink M (1969) EEG and human psychopharmacology. Annu Rev Pharmacol 9:241-258. CrossRef Medline

Fink M (2010) Remembering the lost neuroscience of pharmaco-EEG. Acta Psychiatr Scand 121:161-173. CrossRef Medline

Friston K (2010) The free-energy principle: a unified brain theory? Nat Rev Neurosci 11:127-138. CrossRef Medline

Friston K, Mattout J, Trujillo-Barreto N, Ashburner J, Penny W (2007) Variational free energy and the Laplace approximation. Neuroimage 34: 220-234. CrossRef Medline

Frokjaer VG, Mortensen EL, Nielsen FA, Haugbol S, Pinborg LH, Adams KH, Svarer C, Hasselbalch SG, Holm S, Paulson OB, Knudsen GM (2008) Frontolimbic serotonin $2 \mathrm{~A}$ receptor binding in healthy subjects is associated with personality risk factors for affective disorder. Biol Psychiatry 63:569-576. CrossRef Medline

Gaetz W, Macdonald M, Cheyne D, Snead OC (2010) Neuromagnetic imaging of movement-related cortical oscillations in children and adults: age predicts post-movement beta rebound. Neuroimage 51:792-807. CrossRef Medline

Gaetz W, Edgar JC, Wang DJ, Roberts TP (2011) Relating MEG measured motor cortical oscillations to resting gamma-aminobutyric acid (GABA) concentration. Neuroimage 55:616-621. CrossRef Medline

Gaetz W, Roberts TPL, Singh KD, Muthukumaraswamy SD (2012) Functional and structural correlates of the aging brain: relating visual cortex (V1) gamma band responses to age related structural change. Hum Brain Mapp 33:2035-2046. CrossRef Medline

Glennon RA, Titeler M, McKenney JD (1984) Evidence for 5-HT2 involvement in the mechanism of action of hallucinogenic agents. Life Sci 35: 2505-2511. CrossRef Medline

Goldman RI, Stern JM, Engel J Jr, Cohen MS (2002) Simultaneous EEG and fMRI of the alpha rhythm. Neuroreport 13:2487-2492. CrossRef Medline

Griffiths RR, Richards WA, McCann U, Jesse R (2006) Psilocybin can occasion mystical-type experiences having substantial and sustained personal meaning and spiritual significance. Psychopharmacology (Berl) 187:268283. CrossRef Medline

Griffiths RR, Johnson MW, Richards WA, Richards BD, McCann U, Jesse R (2011) Psilocybin occasioned mystical-type experiences: immediate and persisting dose-related effects. Psychopharmacology (Berl) 218:649-665. CrossRef Medline

Griffiths R, Richards W, Johnson M, McCann U, Jesse R (2008) Mystical-type experiences occasioned by psilocybin mediate the attribution of personal meaning and spiritual significance 14 months later. J Psychopharmacol 22: 621-632. CrossRef Medline

Grob CS, Danforth AL, Chopra GS, Hagerty M, McKay CR, Halberstadt AL, Greer GR (2011) Pilot study of psilocybin treatment for anxiety in pa- tients with advanced-stage cancer. Arch Gen Psychiatry 68:71-78. CrossRef Medline

Hadjipapas A, Adjamian P, Swettenham JB, Holliday IE, Barnes GR (2007) Stimuli of varying spatial scale induce gamma activity with distinct temporal characteristics in human visual cortex. Neuroimage 35:518-530. CrossRef Medline

Hagmann P, Cammoun L, Gigandet X, Meuli R, Honey CJ, Wedeen VJ, Sporns O (2008) Mapping the structural core of human cerebral cortex. PLoS Biol 6:e159. CrossRef Medline

Halberstadt AL, Geyer MA (2011) Multiple receptors contribute to the behavioral effects of indoleamine hallucinogens. Neuropharmacology 61:364-381. CrossRef Medline

Hall EL, Woolrich MW, Thomaz CE, Morris PG, Brookes MJ (2013) Using variance information in magnetoencephalography measures of functional connectivity. Neuroimage 67:203-212. CrossRef Medline

Hall SD, Holliday IE, Hillebrand A, Singh KD, Furlong PL, Hadjipapas A, Barnes GR (2005) The missing link: analogous human and primate cortical gamma oscillations. Neuroimage 26:13-17. CrossRef Medline

Hamandi K, Singh KD, Muthukumaraswamy S (2011) Reduced movementrelated beta desynchronisation in juvenile myoclonic epilepsy: a MEG study of task specific cortical modulation. Clin Neurophysiol 122:2128-2138. CrossRef Medline

Huang MX, Mosher JC, Leahy RM (1999) A sensor-weighted overlappingsphere head model and exhaustive head model comparison for MEG. Phys Med Biol 44:423-440. CrossRef Medline

Hyvärinen A, Oja E (2000) Independent component analysis: algorithms and applications. Neural Netw 13:411-430. CrossRef Medline

Jerbi K, Vidal JR, Ossandon T, Dalal SS, Jung J, Hoffmann D, Minotti L, Bertrand O, Kahane P, Lachaux JP (2010) Exploring the electrophysiological correlates of the default-mode network with intracerebral EEG. Front Syst Neurosci 4:27. CrossRef Medline

Jurkiewicz MT, Gaetz WC, Bostan AC, Cheyne D (2006) Post-movement beta rebound is generated in motor cortex: evidence from neuromagnetic recordings. Neuroimage 32:1281-1289. CrossRef Medline

Kiebel SJ, Garrido MI, Friston KJ (2007) Dynamic causal modelling of evoked responses: the role of intrinsic connections. Neuroimage 36:332345. CrossRef Medline

Klimesch W (2012) Alpha-band oscillations, attention, and controlled access to stored information. Trends Cogn Sci 16:606-617. CrossRef Medline

Krebs TS, Johansen PØ (2012) Lysergic acid diethylamide (LSD) for alcoholism: meta-analysis of randomized controlled trials. J Psychopharmacol 26:994-1002. CrossRef Medline

Lambe EK, Goldman-Rakic PS, Aghajanian GK (2000) Serotonin induces EPSCs preferentially in layer $\mathrm{V}$ pyramidal neurons of the frontal cortex in the rat. Cereb Cortex 10:974-980. CrossRef Medline

Laufs H, Kleinschmidt A, Beyerle A, Eger E, Salek-Haddadi A, Preibisch C, Krakow K (2003) EEG-correlated fMRI of human alpha activity. Neuroimage 19:1463-1476. CrossRef Medline

Le Van Quyen M, Foucher J, Lachaux J, Rodriguez E, Lutz A, Martinerie J, Varela FJ (2001) Comparison of Hilbert transform and wavelet methods for the analysis of neuronal synchrony. J Neurosci Methods 111:83-98. CrossRef Medline

Litvak V, Eusebio A, Jha A, Oostenveld R, Barnes GR, Penny WD, Zrinzo L, Hariz MI, Limousin P, Friston KJ, Brown P (2010) Optimized beamforming for simultaneous MEG and intracranial local field potential recordings in deep brain stimulation patients. Neuroimage 50:1578-1588. CrossRef Medline

Logothetis NK, Pauls J, Augath M, Trinath T, Oeltermann A (2001) Neurophysiological investigation of the basis of the fMRI signal. Nature 412: 150-157. CrossRef Medline

Lorincz ML, Kékesi KA, Juhász G, Crunelli V, Hughes SW (2009) Temporal framing of thalamic relay-mode firing by phasic inhibition during the alpha rhythm. Neuron 63:683-696. CrossRef Medline

MacLean KA, Johnson MW, Griffiths RR (2011) Mystical experiences occasioned by the hallucinogen psilocybin lead to increases in the personality domain of openness. J Psychopharmacol 25:1453-1461. CrossRef Medline

Maris E, Oostenveld R (2007) Nonparametric statistical testing of EEG- and MEG-data. J Neurosci Methods 164:177-190. CrossRef Medline

Meyer JH, McMain S, Kennedy SH, Korman L, Brown GM, DaSilva JN, Wilson AA, Blak T, Eynan-Harvey R, Goulding VS, Houle S, Links P 
(2003) Dysfunctional attitudes and 5-HT2 receptors during depression and self-harm. Am J Psychiatry 160:90-99. CrossRef Medline

Moran RJ, Kiebel SJ, Stephan KE, Reilly RB, Daunizeau J, Friston KJ (2007) A neural mass model of spectral responses in electrophysiology. Neuroimage 37:706-720. CrossRef Medline

Moran RJ, Stephan KE, Seidenbecher T, Pape HC, Dolan RJ, Friston KJ (2009) Dynamic causal models of steady-state responses. Neuroimage 44:796-811. CrossRef Medline

Moran RJ, Symmonds M, Stephan KE, Friston KJ, Dolan RJ (2011) An in vivo assay of synaptic function mediating human cognition. Curr Biol 21:1320-1325. CrossRef Medline

Moreno FA, Wiegand CB, Taitano EK, Delgado PL (2006) Safety, tolerability, and efficacy of psilocybin in 9 patients with obsessive-compulsive disorder. J Clin Psychiatry 67:1735-1740. CrossRef Medline

Murakami S, Okada Y (2006) Contributions of principal neocortical neurons to magnetoencephalography and electroencephalography signals. J Physiol 575:925-936. CrossRef Medline

Muthukumaraswamy SD, Singh KD (2013) Visual gamma oscillations: the effects of stimulus type, visual field coverage and stimulus motion on MEG and EEG recordings. Neuroimage 69:223-230. CrossRef Medline

Muthukumaraswamy SD (2010) Functional properties of human primary motor cortex gamma oscillations. J Neurophysiol 104:2873-2885. CrossRef Medline

Muthukumaraswamy SD (2011) Temporal dynamics of primary motor cortex gamma oscillation amplitude and piper corticomuscular coherence changes during motor control. Exp Brain Res 212:623-633. CrossRef Medline

Muthukumaraswamy SD, Edden RA, Jones DK, Swettenham JB, Singh KD (2009) Resting GABA concentration predicts peak gamma frequency and fMRI amplitude in response to visual stimulation in humans. Proc Natl Acad Sci U S A 106:8356-8361. CrossRef Medline

Muthukumaraswamy SD, Singh KD, Swettenham JB, Jones DK (2010) Visual gamma oscillations and evoked responses: variability, repeatability and structural MRI correlates. Neuroimage 49:3349-3357. CrossRef Medline

Muthukumaraswamy SD, Myers JF, Wilson SJ, Nutt DJ, Hamandi K, Lingford-Hughes A, Singh KD (2013a) Elevating endogenous GABA levels with GAT-1 blockade modulates evoked but not induced responses in human visual cortex. Neuropsychopharmacology 38:1105-1112. CrossRef Medline

Muthukumaraswamy SD, Myers JF, Wilson SJ, Nutt DJ, Lingford-Hughes A, Singh KD, Hamandi K (2013b) The effects of elevated endogenous GABA levels on movement-related network oscillations. Neuroimage 66: 36-41. CrossRef Medline

Nichols TE, Holmes AP (2002) Nonparametric permutation tests for functional neuroimaging: a primer with examples. Hum Brain Mapp 15:1-25. CrossRef Medline

Ossandón T, Jerbi K, Vidal JR, Bayle DJ, Henaff MA, Jung J, Minotti L, Bertrand O, Kahane P, Lachaux JP (2011) Transient suppression of broadband gamma power in the default-mode network is correlated with task complexity and subject performance. J Neurosci 31:14521-14530. CrossRef Medline

Pelli DG (1997) The VideoToolbox software for visual psychophysics: transforming numbers into movies. Spat Vis 10:437-442. CrossRef Medline

Perry G, Hamandi K, Brindley LM, Muthukumaraswamy SD, Singh KD (2013) The properties of induced gamma oscillations in human visual cortex show significant individual variability in their dependence on stimulus size. Neuroimage 68:83-92. CrossRef Medline

Puig MV, Watakabe A, Ushimaru M, Yamamori T, Kawaguchi Y (2010) Serotonin modulates fast-spiking interneuron and synchronous activity in the rat prefrontal cortex through $5-\mathrm{HT}_{1 \mathrm{~A}}$ and $5-\mathrm{HT}_{2 \mathrm{~A}}$ receptors. J Neurosci 30:2211-2222. CrossRef Medline

Raichle ME, Snyder AZ 2007 A default mode of brain function: a brief history of an evolving idea. Neuroimage 37:1083-1090. CrossRef Medline

Raichle ME, MacLeod AM, Snyder AZ, Powers WJ, Gusnard DA, Shulman GL (2001) A default mode of brain function. Proc Natl Acad Sci U S A 98:676-682. CrossRef Medline

Riba J, Anderer P, Jané F, Saletu B, Barbanoj MJ (2004) Effects of the South American psychoactive beverage ayahuasca on regional brain electrical activity in humans: a functional neuroimaging study using low-resolution electromagnetic tomography. Neuropsychobiology 50:89-101. CrossRef Medline

Robinson SE, Vrba J (1999) Functional neuroimaging by synthetic aperture manetometry (SAM). In: Recent advances in biomagnetism (Yoshimoto T, Kotani M, Kuriki S, Karibe H, Nakasato N, eds), pp 302-305. Sendai, Japan: Tohoku UP.

Saxena N, Muthukumaraswamy SD, Diukova A, Singh K, Hall J, Wise R (2013) Enhanced stimulus-induced gamma activity in humans during propofol-induced sedation. PLoS One 8:e57685. CrossRef Medline

Scheeringa R, Fries P, Petersson KM, Oostenveld R, Grothe I, Norris DG, Hagoort P, Bastiaansen MC (2011) Neuronal dynamics underlying high- and low-frequency EEG oscillations contribute independently to the human BOLD signal. Neuron 69:572-583. CrossRef Medline

Schwarzkopf DS, Robertson DJ, Song C, Barnes GR, Rees G (2012) The frequency of visually induced gamma-band oscillations depends on the size of early human visual cortex. J Neurosci 32:1507-1512. CrossRef Medline

Silva LR, Amitai Y, Connors BW (1991) Intrinsic oscillations of neocortex generated by layer 5 pyramidal neurons. Science 251:432-435. CrossRef Medline

Singh KD, Barnes GR, Hillebrand A, Forde EM, Williams AL (2002) Taskrelated changes in cortical synchronization are spatially coincident with the hemodynamic response. Neuroimage 16:103-114. CrossRef Medline

Singh KD, Barnes GR, Hillebrand A (2003) Group imaging of task-related changes in cortical synchronisation using nonparametric permutation testing. Neuroimage 19:1589-1601. CrossRef Medline

Smith SM (2002) Fast robust automated brain extraction. Hum Brain Mapp 17:143-155. CrossRef Medline

Sun W, Dan Y (2009) Layer-specific network oscillation and spatiotemporal receptive field in the visual cortex. Proc Natl Acad Sci U S A 106:17986-17991. CrossRef Medline

Supekar K, Uddin LQ, Prater K, Amin H, Greicius MD, Menon V (2010) Development of functional and structural connectivity within the default mode network in young children. Neuroimage 52:290-301. CrossRef Medline

Swettenham JB, Muthukumaraswamy SD, Singh KD (2009) Spectral properties of induced and evoked gamma oscillations in human early visual cortex to moving and stationary stimuli. J Neurophysiol 102:1241-1253. CrossRef Medline

Van Essen DC, Dierker DL (2007) Surface-based and probabilistic atlases of primate cerebral cortex. Neuron 56:209-225. CrossRef Medline

Vollenweider FX, Vollenweider-Scherpenhuyzen MF, Bäbler A, Vogel H, Hell D (1998) Psilocybin induces schizophrenia-like psychosis in humans via a serotonin-2 agonist action. Neuroreport 9:3897-3902. CrossRef Medline

Vrba J, Robinson SE (2001) Signal processing in magnetoencephalography. Methods 25:249-271. CrossRef Medline

Weber ET, Andrade R (2010) Htr2a gene and 5-HT(2A) receptor expression in the cerebral cortex studied using genetically modified mice. Front Neurosci 4:36. CrossRef Medline

Whitfield-Gabrieli S, Ford JM (2012) Default mode network activity and connectivity in psychopathology. Annu Rev Clin Psychol 8:49-76. CrossRef Medline

Whitham EM, Pope KJ, Fitzgibbon SP, Lewis T, Clark CR, Loveless S, Broberg M, Wallace A, DeLosAngeles D, Lillie P, Hardy A, Fronsko R, Pulbrook A, Willoughby JO (2007) Scalp electrical recording during paralysis: quantitative evidence that EEG frequencies above $20 \mathrm{~Hz}$ are contaminated by EMG. Clin Neurophysiol 118:1877-1888. CrossRef Medline

Whitham EM, Lewis T, Pope KJ, Fitzgibbon SP, Clark CR, Loveless S, DeLosAngeles D, Wallace AK, Broberg M, Willoughby JO (2008) Thinking activates EMG in scalp electrical recordings. Clin Neurophysiol 119:1166-1175. CrossRef Medline

Wood J, Kim Y, Moghaddam B (2012) Disruption of prefrontal cortex large scale neuronal activity by different classes of psychotomimetic drugs. J Neurosci 32:3022-3031. CrossRef Medline

Zou Q, Wu CW, Stein EA, Zang Y, Yang Y (2009) Static and dynamic characteristics of cerebral blood flow during the resting state. Neuroimage 48:515-524. CrossRef Medline 